\title{
Accounting Measures and Economic Measures: An Integrated Theory of Capital Budgeting
}

\author{
Carlo Alberto Magni \\ University of Modena and Reggio Emilia
}

Accounting measures are traditionally matched against economic measures. For example, accounting rates of return (ARR) are usually considered poor surrogates of the "economic rate of return" and the residual income is sometimes criticized as being periodically inconsistent with the net present value $(N P V)$. This paper shows that the opposition accounting/economic is artificial and, taking a capital budgeting perspective, illustrates the strict links between economic measures and accounting measures. In particular, the ARR is shown to be a correct economic yield of a project and the traditional IRR is only a particular case of it. Also, maximization of the simple arithmetic mean of properly modified residual incomes is equivalent to NPV maximization, owing to its periodic consistency in the sense of Egginton (1995). The conciliation of such notions as NPV, IRR, ARR, and residual income stems from (i) the fundamental law of motion of any economic entity, (ii) the notion of Chisini mean, (iii) a modified notion of residual income which takes account of a comprehensive cost of capital.

Keywords. Capital Budgeting, Accounting Rate of Return, Economic Yield, Internal Rate of Return, Residual Income, Net Present Value, Average, Chisini Mean, Cost of Capital

\section{INTRODUCTION}

This paper explores the mathematical relations between accounting measures such as accounting rate of return (ARR) and residual income (RI) on one side, and economic measures such as the internal rate of return (IRR) and the net present value (NPV) on the other side. The ARR is usually considered economically meaningless or, at the very best, a poor surrogate for the IRR. The IRR has a respectable ancestry (Boulding, 1935, 1936a, b; Keynes, 1936) and is massively used by managers and analysts. Great effort has been spent by scholars in past years to provide a way of linking accounting rates to the IRR. As the latter is considered the "true" yield, the ARR may be given an economic role if and only if it bears some significant relation to the IRR. Numerous scholars have complained that accounting rates are not susceptible to be easily reconciled with the IRR; hence, "it is widely presumed in the accounting and economic literatures that, for the most part in practice, ARRs are artifacts without economic significance." (Peasnell, 1982a, p. 368). The pitfalls in using ARRs in place of economic rates of return has been investigated across several decades of academic research, both theoretical and empirical (e.g. Harcourt, 1965; Solomon, 1966; Livingstone and Salamon, 1970; Gordon, 1974; Kay, 1976; Peasnell, 1982a,b; Fisher and McGowan, 1983; Luckett, 1984; Salamon, 1985; Kay and Mayer, 1986; Gordon and Stark, 1986; Whittington, 1988; Peasnell, 1996; Stark, 2004. See also Feenstra and Wang's, 2000, review and references therein). Some connections between Return On Investment (ROI) and IRR have been 
established by Rajan et al. (2007), based on different assumptions on the growth in new investments and the degree of accounting conservatism (see also Gjesdal, 2007). Conservative (respectively, liberal) accounting occurs if investments are written off faster (respectively, slower) than they would have been in neutral accounting; the latter is, by definition, a system of capital depreciation such that the resulting ROI is constant over time; in this case, it is well-known that ROI and IRR are exactly the same index.

A most desirable result would be the coincidence of the IRR with the average of ARRs, weighted by book values. Unfortunately, this seems not to be the case:

Is the average ARP [accounting rate of profit] equal to the IRR in a more obvious sense of average? The general answer is no: it will not normally be true that

$$
\bar{a}=\frac{\int_{0}^{\infty} a(t) v(t) d t}{\int_{0}^{\infty} v(t)}=r
$$

where $\bar{a}$ is the natural definition of an average ARP. (Kay, 1976, p. 451, italics supplied) ${ }^{1}$

Because the ARR manifests a clear analytical link to the IRR only under exceptional circumstances (e.g., if the ARR is constant, then it coincides with the IRR), ${ }^{2}$ it is widely believed that comparing the ARR with the cost of capital is "clearly like comparing apples with oranges" (Rappaport, 1986, p. 31).

Residual income is another important notion in accounting. It is extensively used in the accounting and finance literature for two main purposes: on one hand, it being a periodic measure, it is used for performance measurement and incentive compensation (see Solomons, 1965; Grinyer, 1985, 1987; Stewart, 1991; Gallo and Peccati, 1993; Rogerson, 1997; Reichelstein, 1997; Martin and Petty, 2000; Arnold and Davies, 2000; Pfeiffer, 2000; 2004; Young and O'Byrne, 2001; Mohnen, 2003; Baldenius and Reichelstein, 2005; Mohnen and Bareket, 2007; Pfeiffer and Schneider, 2007); on the other hand, it is used for project/firm valuation (Preinreich, 1936, 1937, 1938; Peasnell, 1981, 1982a,b; Peccati, 1987, 1989; Ohlson, 1989, 1995; Feltham and Ohlson, 1995; Lundholm and O'Keefe, 2001; O'Hanlon and Peasnell, 2002; Penman, 2007) owing to its lifespan consistency with the NPV: the sum of discounted residual incomes is equal to NPV (see Preinreich, 1936, 1938; Lücke, 1955; Edey, 1957; Edwards and Bell, 1961; Bodenhorn, 1964; Peasnell, 1981, 1982a,b; Edwards, Kay, and Mayer 1987; Peccati, 1989; Brief and Peasnell, 1996; Martin and Petty, 2000; Fernàndez, 2002; Martin, Petty and Rich, 2003; Pfeiffer, 2004; Magni, 2009a, 2010a); however, periodic consistency does not hold in general (Egginton, 1995. But see Anctil, 1996; Anctil, Jordan and Mukherji, 1998, for exceptions) and ranking projects with $\mathrm{RI}$ is not equivalent to NPV ranking.

The quest for a reconciliation between economic measures and accounting measures is compelling, as has been often underlined by accounting scholars:

For reasons mostly of familiarity and convenience, accounting measures of return continue to be widely used. It is therefore desirable to have an analysis which pinpoints precisely when, how and why the accounting measures differ from the economic measures. (Franks and Hodges, 1984, p.133)

To the extent that cash-flow capital budgeting measures appear to managers incapable of being arithmetically reconciled with the now familiar accounting measures, then there is a danger that they will not receive the attention they deserve. In these circumstances, there is a lot to be said for presenting the project data in a manner such that the arithmetical connections with accounting profits is made obvious. (Peasnell, 1982a, p. 376 , italics supplied)

Capital budgeting, especially, is one research area where "the use of accounting numbers (alongside, in competition with, even to the exclusion of the economic measures) has persisted to an extent which has both surprised and frustrated many financial theorists" (Peasnell, 1982a, p. 376). This work just aims at 
showing that the opposition accounting indexes/economic measures derives from misconceiving such relations, and provides, at the same time, a theory of capital budgeting which integrates and harmonizes economics and accounting. Focusing on the mathematical connections with accounting profits, as suggested by Peasnell (1982a), we show that such clear-cut statements as 1.-4. below are (at the best) overstatements, and the poor status attributed to ARRs is due to (i) a misleading definition of economic yield, according to which it is the constant return rate that makes the discounted-cash-flow function equal to zero, and to (ii) a restrictive notion of residual income, which views the capital charge as the product of the normal rate of profit (NRP) and the capital invested in the project.

1. Accounting rates of return, even if properly and consistently measured, provide almost no information about economic rates of return ... Accounting rates of return are useful only insofar as they yield information as to economic rates of return (Fisher and McGowan, 1983, p. 82)

2. If the economic rate of return fails to be unique, then, while present value calculations using the cost of capital remain the correct method for analyzing profitability, profitability cannot be summarized by any rate of return, including accounting rates of return. (Fisher and McGowan, 1983, p. 83)

3. There is no way in which one can look at accounting rates of return and infer anything about relative economic profitability. (Fisher and McGowan, 1983, p. 90)

4. The answer provided by the true yield method is the correct one and ... it is the book-yield measure which is in error. (Solomon, 1966, pp. 233-234, as quoted in Vatter, 1966, p. 683)

We show that a more useful definition of economic yield dispenses with the discounted-cash-flow function and makes use of residual income; and that an appropriate capital charge for RI takes into consideration (not one but) two kinds of opportunity costs suffered by the investor: the normal rate of profit and the normal capital, a neglected concept in accounting and finance. The former is the rate of return at which investors could alternatively invest their funds. The latter is the value of the capital investors would invest if they replicated the project's cash flows by investing their funds at the NRP. Comparisons between accounting rates and an appropriate cost of capital correctly capture economic profitability, and the much neglected average ARR is a meaningful internal economic yield. As opposed to the IRR, the average ARR gives no problem of existence nor uniqueness.

Further, we show that maximization of the simple arithmetic mean of RI is equivalent to maximization of NPV. This average RI, which is invariant under changes in the asset base, coincides with the constant RI associated with a well-determined book value depreciation, where the above-normal capital is constant over time. This constant RI is called maintainable RI, in analogy with Egginton's (1995). The average RI and the maintainable RI (possibly time-scaled for projects of unequal life) enjoy periodic consistency in the sense of Egginton (1995).

The average ARR, the average RI and the NPV are actually interpretable as the same notion viewed in different terms:

- the NPV is the average RI multiplied by the market value of project's length;

- the average ARR is the sum of the average cost of capital and the accumulated NPV generated by one unit of capital invested;

- the simple average income is the sum of the average capital charge per period and the period accumulated NPV.

And the normal rate of profit may be interpreted as the cost of capital corresponding to a welldetermined class of depreciation schedules.

The reconciliation of accounting and economic measures extends to valuation: it is shown that a project's value is a linear affine function of the simple arithmetic mean of incomes. This implies that forecasting errors are reduced: there is no need of forecasting each and every income but only the average income, appropriately net of an average capital charge. Furthermore, the unit price of a zero-coupon bond expiring at time $t$ is equal to the derivative of any $t$-period asset's value with respect to an income increase occurred at any time within the span $[0, t]$. In other words, the yield term structure is described by the 
market-determined effects of income on the asset's value, which implies that any asset's value is a linear combination of such income effects, with cash flows as coefficients.

It is evident that the results obtained also have relevant educational implications as well: to explain economic notions such as NPV, IRR, and yield term structure by resorting to familiar accounting concepts implies that such economic concepts and measures will be more easily comprehended in the real-life accounting domains.

The theory developed in this paper stems in a natural way from three theoretical notions. They play a major role in linking accounting measures and economic measures:

1. the notion of lost-capital residual income introduced and fostered by Magni (see Magni, 2009a, 2010a, 2012), according to which the appropriate cost of capital incorporates information not only on the foregone rate of return (normal rate of profit) but also on the above-normal capital investors would own if they accepted the project

2. the law of motion (also known as clean surplus relation), which chains accounting income to cash flows and represents an important link between finance and accounting (see Brief and Peasnell, 1996)

3. the notion of Chisini mean (Chisini, 1929), which is based on an invariance requirement according to which a mean should simplify the problem under consideration by replacing several observations with a unique value so that the overall evaluation of the problem remains unchanged.

The paper is structured as follows. In the first section, the three fundamental ingredients of the theory are presented and commented, and some preliminary results are shown. The second section is devoted to ARR-based capital budgeting and shows that the project is profitable if and only if the average ARR is greater than the average cost of capital and that project ranking through the difference between average ARR and average cost of capital is correct. The third section is devoted to showing that book value is underdetermined by data and that the traditional IRR is but an average ARR corresponding to a welldetermined depreciation class. The fourth section is devoted to RI-based capital budgeting and shows that maximization of the average RI is equivalent to NPV maximization. The fifth section focusses on valuation and on the equivalence of the yield term structure with the market-determined effect of an income increase on an asset's value. The sixth section offers some reflections on educational implications. A summary of the results obtained concludes the paper.

\section{The Three Links and Some Preliminary Results}

Consider asset $F$ generating the cash flows $F_{t}, t=1,2, \ldots, \quad, \in \mathbb{N}$. The asset may be thought of as a project, a firm, a financial investment, a loan contract etc. The amount $F_{t}$ represents the "dividend" expected at time $t$ by the owners of the asset, and $F_{T}$ is inclusive of the liquidation value of the project (i.e., it is the sum of the last dividend and the residual value distributed to capital providers at time $T$ ). Let $b_{0}=-F_{0} 0$ be the initial capital invested. Let $\vec{r}=\left(r_{1}, 2, \ldots, T\right)$ represent the vector of normal rates of profit and denote the discount factor. The reader may regard cash flows as certain or certainty equivalents of random cash flows; in this case, the vector of NRPs represent the unit price of zero-coupon bonds (i.e., the yield term structure); if, conversely, the reader prefers to consider cash flows uncertain, then the vector of NRPs is the vector of expected return rates of equivalent-risk assets traded in the market. ${ }^{3}$ The analysis obviously holds for ex post valuation as well.

$$
v(\vec{r}), t:=\frac{1}{\left.\left(1 \quad r_{k+1}\right)(1 \quad k+2) \cdots 1+r_{t}\right)} \quad k, t=0,1, \ldots, T \quad k \leq t
$$

The value of the asset is classically obtained as

$V=\sum_{t=1}^{n} F_{t} \cdot(\vec{r}), 0$. 
The project's Net Present Value (NPV) is given by

$\mathrm{NPV}=V-C_{0}$.

The asset is worth undertaking if and only if NPV $=\operatorname{NPV}(\vec{r}) \quad 0$ for a fixed $r \in \mathbb{R}^{T}$. We will also make use of the notion of time- $t$ (accumulated) NPV, which is the NPV compounded to a future date: $\mathrm{NPV}_{t}:=\mathrm{NPV} \cdot u(\vec{r}), \quad$, where $u(\vec{r}), t: 1 / v(r), t$ is the accumulation factor.

\section{Accounting Identity (AI)}

Accounting profit $x_{t}$ is such that

$$
x_{t}-F_{t}=b_{t}-b_{t-1} \quad t=1,2, \ldots, T
$$

where $b_{t}$ may be alternatively viewed as the book value of assets (entity perspective) or the book value of equity (equity perspective). The above relation is often named clean surplus relation. In other words, there are two sources of change in book value: income and cash flows.

Let $\vec{a}$ be the vector of accounting rates of return, whose $t$-th component is $a_{t}: \frac{x_{t}}{b_{t-1}}$; AI may be rewritten as

$b_{t}=b_{t-1}(1 \quad t)-F_{t} \quad t=1,2, \ldots, T, \quad b_{0}=-F_{0}$.

The above equation is enlightening: it gives one the law of motion of any economic system's capital; it says that the capital invested increases at the rate $a_{t}$ and decreases by the dividend paid to claimholders. Equation (3) is the common recurrence equation for the amortization plan of a loan: the capital $b_{t}$ invested in a firm may then be viewed as the residual debt owed by the firm, $a_{t}$ is the interest rate, and $F_{t}$ is the installment paid at time $t$. This interpretation likens the undertaking of a project (firm) to the stipulation of a loan. The loan is ideally represented by the investors' legal rights: "The corporation owes the capital, it does not own it. The shareholders own it" (Fetter, 1937, p. 9); and income is viewed as interest: "the profit is equal to interest on the capital value existing at the beginning of the period" (Hansen, 1972, p. 15). (Anthony, 1975, as well, views profit as a shareholders' credit. See Magni, 2010a).

While the notion of internal rate of return (IRR) is well-rooted in the literature since its conception by Boulding $(1935,1936)$ and Keynes $(1936)$, it is worth noting that, formally, the IRR notion is only a particular case of the more general notion of internal return vector introduced by Weingartner (1966): an internal return vector is a vector $\vec{l}=\left(i_{1}, 2, \ldots, T\right)$ such that $\operatorname{NPV}(\vec{l}) \quad 0$. This notion collapses into the IRR notion if rates are constant in each period: $\vec{\imath}=(i, \ldots$, ) (see also Kay, 1976, Peasnell, 1982a; Edwards, Kay and Mayer, 1986; Peccati, 1989).

Using induction on (3), one finds

$b_{T}=-\sum_{t=0}^{T} F_{t} \cdot(\vec{a}), T$.

After distribution of $F_{T}$ (last dividend plus liquidation value), the book value is zero: $b_{T} 0$. Hence, a proper replacement of the accumulation factor with the discount factor and a change in sign lead to

$0 \quad \sum_{t=0}^{T} F_{t} \cdot(\vec{a}), \quad \mathrm{N} \quad \mathrm{PV}(\vec{a})$

where the dependence of the NPV on the ARR-vector is highlighted. Because (5) holds for all $a \in R^{T}$ satisfying (3) and the boundary condition $b_{T} 0$, any sequence of accounting rates is an internal return vector. In the light of eqs. (3) and (5), accounting rates of return are one-period internal rates of return. In particular, one may interpret any asset $F$ as a portfolio of one-period projects where $b_{t-1}$ is the initial 
capital invested, and $b_{t}+F_{t}$ represents the cum-dividend end-of-period value. The IRR of this one-period

project is, actually, the ARR: $\frac{b_{t}+F_{t}}{b_{t-1}} 1=\frac{x_{t}}{b_{t-1}}=a_{t}$. The ARRs are thus themselves internal rates of return, and the return vector determined by the ARRs leads to a zero NPV.

We now give the notion of mean introduced by Chisini (1929) (see also Muliere and Parmigiani, 1993; de Finetti, 2008; Graziani and Veronese, 2009). The idea of Chisini is that one should not think about the mean of two or more values, but think about the mean of those values with reference to the evaluation of a quantity that depends on them, such that by replacing the values with a unique summary value, the overall picture of the problem remains unaltered. This is the so-called invariance requirement. More formally:

\section{Chisini Mean}

The Chisini mean of $T$ values $m_{1}, 2, \ldots, \quad T$, associated with a function $f$, is defined as the number $m$, if it exists and is unique, such that

$$
f(, \quad, \quad \ldots, m)=f\left(m_{1}, \quad 2, \ldots, \quad T\right) .
$$

In other words, the Chisini mean is the unique number $m$ replacing $m_{1}, 2, \ldots, \quad{ }_{T}$ which leaves the value of $f$ unchanged. We stress that the function must be chosen in such a way that there always exists exactly one number $m$ with this property and that the notion of Chisini mean must be interpreted with respect to a given function.

Significantly, if the IRR exists and is unique, it is a Chisini mean of ARRs. To see it, just take a glance on (5) and consider the function $g\left(a_{1}, 2, \ldots, T\right):=\operatorname{NPV}(\vec{a})$. The Chisini mean of the ARRs associated with $g$ is the real number $a$ such that

$$
g\left(a_{1}, 2, \ldots, \quad T\right)=g(, \quad, \ldots, a)
$$

Given that $g\left(a_{1}, 2, \ldots, T\right)$ is identically zero (any vector of ARRs is an internal return vector), the mean $a$ is an internal rate of return:

$$
0 \quad 0_{0}+\sum_{t=1}^{T} F_{t} v(a), t \quad \mathrm{~N} \quad \mathrm{PV}(a)=g(, \quad, \ldots, a) .
$$

Therefore, the usual definition of IRR is just a definition of mean in the sense of Chisini. Its meaning is clear: it is the constant accounting rate (if it exists) that makes the final book value $b_{T}$ be equal to zero (i.e., NPV=0) (see also Kay, 1976; Peasnell, 1982a; Franks and Hodges, 1984; Brief and Lawson, 1992). It must be noted that a solution of eq. (6) is not guaranteed for any project, that is, for any vector of cash flows; nor is it guaranteed the uniqueness of the solution. Formally, this means that it is not always possible to extract the Chisini mean of ARRs from eq. (6). This implies that the choice of function $g$ above is unfortunate. Hence, we have the following

Proposition 1.1. The IRR exists and is unique if and only if it is the Chisini mean of the ARRs associated with function $N P V(\vec{a})$.

The IRR signals value creation if and only if $i-r>0$. Whenever the IRR does not exist or multiple roots arise, this rule is inapplicable. This implies the following

Corollary 1.1 The IRR rule may not be used for capital budgeting if the IRR is not a Chisini mean of the ARRs associated with function NPV $(\vec{a})$.

A plethora of problems come along with the IRR rule. We may collect them in five classes:

a) the IRR may not exist (roots are complex-valued) ${ }^{4}$ 
b) the IRR may be not unique ${ }^{5}$

c) even if the IRR exists and is unique, it does not correctly signal economic profitability if the NPV function is negative for $i \neq r .{ }^{6}$

d) the IRR rule is incompatible with the NPV rule in project ranking

e) the IRR rule is inapplicable with variable NRPs.

These problems are well-known in the economic literature. ${ }^{7}$ A substantial amount of contributions have been devoted to them and to proposals for mitigating the IRR's awkwardness (e.g., Boulding, 1935, 1936b, Samuelson, 1946; Lorie and Savage, 1955; Solomon, 1956; Hirshleifer, 1958; Pitchford and Hagger, 1958; Bailey, 1959; Karmel, 1959; Soper, 1959; Wright, 1959; Kaplan, 1965, 1967; Jean, 1968; Arrow and Levhari, 1969; Adler, 1970; Ramsey, 1970; Norstrøm, 1971; Flemming and Wright, 1971; Aucamp and Eckardt, 1976; Bernhard, 1977, 1979; Herbst, 1978; Ross, Spatt and Dybvig, 1980; Dorfman, 1981; Gronchi, 1986; 1987; Hajdasinski, 1986, 2004; Promislow and Spring, 1996; Bernhard, 2003; Hazen, 2003, 2009; 8 Rocabert, Tarrío, Pérez, 2005; Kierulff, 2008; Magni, 2013).

Among various proposals that seek to heal the IRR inconsistencies we consider the one provided by Teichroew, Robichek and Montalbano (1965a,b) and, in later years, by Gronchi (1987). The decision rule purported by these authors assumes a constant normal rate of profit $r$ and is based on some results that are summarized in the following proposition.

Proposition 1.2 Assume the normal rate of profit is constant over time. If $i$ is an IRR of the project and $\sum_{k=0}^{t} F_{k}\left(\begin{array}{ll}1 & r\end{array}\right)^{t-k} 0$ for $1<T$, then the IRR is unique and the NPV is positive if and only if $i-r>0$. (See Soper, 1959; Gronchi, 1986, 1987).

In an accounting perspective, reminding that the IRR-determined depreciation pattern is also known as Hotelling depreciation (Hotelling, 1925), ${ }^{9}$ the above proposition may be restated in the following way.

Proposition 1.2 (Restated). Assume the normal rate of profit is constant over time. If $i$ is an IRR of the project and Hotelling depreciation is such that book value $b_{t}$ is nonnegative for $1<T$, then the IRR is unique and the NPV is positive if and only if $i-r>0$.

The projects which meet the assumption of Proposition 1.2 are called "Soper projects". Note that if a project is not a Soper project, then a Hotelling schedule is such that $b_{t} 0$ for some $t>0$. Teichroew, Robichek and Montalbano (1965a,b) and Gronchi (1987) find the following result

Proposition 1.3. Suppose a project does not belong to the class of Soper projects. Then, there exists a pair of return rates $\left(i_{-},+\right) \in\left(1,+\infty \times\left(1,+\infty\right.\right.$ such that and such that $b_{T}=b_{T}\left(i_{-},+\right) \quad 0 \quad$ (i.e., $N P V=0)$. In particular, the latter equation defines an implicit function $i_{+}=i_{+}\left(i_{-}\right)$which is continuous and increasing.

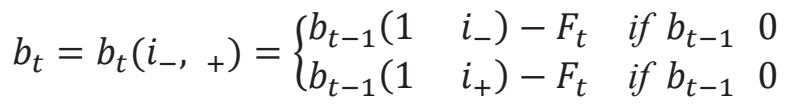

The two rates, which we will name "minus rate" and "plus rate" respectively, are evidently an internal pair. In our perspective, we may interpret the vector $\vec{a}$ of accounting rates as an internal return vector such that the accounting rate is equal to the minus rate if Hotelling book value is negative and equal to the plus rate in the opposite case. The results obtained by these authors enable to derive a decision rule, here denoted with the acronym of the authors' names, which is summarized as follows: ${ }^{10}$

TRMG Rule. If the assumptions of Proposition 1.2 are fulfilled, choose a pair $\left(i_{-},+\right)$such that $i_{-}=r$. Then, undertake the project if and only if $i_{+}(r)-r>0$. 
The idea is that of using the NRP as the minus rate and computing the corresponding plus rate. If and only if the plus rate is greater than the NRP, then the project is worth undertaking. If one leaves aside practical issues (how is $i_{+}(r)$ computed?), from a theoretical point of view the TRMG rule solves problems a), b), and c), while leaving untouched problems d) and e). While the authors were completely of a possible accounting interpretation, their result is the earliest one in the literature (as far as we can tell) that serves the purpose of giving economic significance to accounting rates: the authors actually supply a particular case where a decision rule based on an accounting rate is superior to the traditional IRR rule. In essence, they unawarely proved that, under suitable circumstances, accounting rates of return suffice to make a decision:

TRMG Rule (Restated). If book value depreciation is such that the vector of accounting rates is composed of two rates, one of which is equal to the NRP and is applied to negative book values, then the $N P V$ is positive if and only if the accounting rate applied to the positive book values is greater than the accounting rate applied to the negative book value (i.e., the NRP).

The ARR notion derives from the income notion, and the latter is a fundamental ingredient of residual income. The standard theory suggests that RI should be computed as income in excess of normal interest on book value: $\mathrm{RI}_{t}:=x_{t}-r_{t} b_{t-1}$. However, this means that the project's income is compared with the income of a portfolio which replicates the project's book values in the capital market. Put it differently, the capital charge is $r_{t} b_{t-1}$ if (and only if) $b_{t-1}$ is equal to the market value of such a replicating portfolio at time $t-1$. However, investors might well replicate cash flows (instead of capital values). In other words, investors might replicate the project's cash-flow stream $\left(F_{0}, 1, \ldots, n\right)$ in the market while earning $r_{t}$ on the invested capital. Under this perspective, starting from $t=0$, investors invest $b_{0}=-F_{0}$ at the market rate $r_{1}$ and then withdraw $F_{1}$ from the replicating portfolio at time 1 . The portfolio's market value at the beginning of the second period is then $b_{1}^{*}=b_{0}\left(\begin{array}{ll}1 & 1\end{array}\right)-F_{1}$, which differs from $b_{1}$. Hence, the foregone income in the third period is $r_{1} b_{1}^{*}$, not $r_{1} b_{1}$. The former is a capital charge which reflects the fact that, if investors replicated the project's cash flows in the market (instead of values), they would earn a different rate of return on a different invested capital. This line of reasoning is iterated leading to nonstandard capital charges $r_{t} b_{t-1}^{*}$ and, hence, to a nonstandard definition of RI, which comprehends all the opportunity costs suffered by the investor (foregone rate of return and foregone capital) and which, as we will see, provides simple and intuitive connections between accounting values and economic values.

In general, consider the normal rate of profit $r_{t}$, holding in the interval $[t-1, t]$ : it is the rate of return foregone by the investor. Let $b_{t}^{*}$ represent the normal capital, that is, the capital invested by the owners of the asset if the period rate of return were the NRP, assuming equal cash flows. We have

$b_{t}^{*}: \quad b_{t-1}^{*}(1 \quad t)-F_{t} \quad t=1,2, \ldots, T \quad$ with $\quad b_{0}^{*}=-F_{0}$

The normal capital is labelled "unrecovered capital" by O'Hanlon and Peasnell (2002), "lost capital" by Magni (2009a, 2010a). We state the following (nonstandard) definition of residual income.

Residual Income definition (RID). Residual income is income in excess of the return on normal capital:

$\mathrm{RI}_{t}: \quad x_{t}-r_{t} b_{t-1}^{*}$

(see Magni, 2009a, 2010a, 2016 for relations with arbitrage theory and with the traditional definition of residual income. See also Ghiselli Ricci and Magni, 2009, for an axiomatic approach). Let us focus on the interpretation of such a residual income. Firstly, note that the definition of normal capital is just a clean surplus relation: actually, it is eq. (3) (i.e., AI) where the NRP replaces the accounting rate. Hence, the capital charge $r_{t} b_{t-1}^{*}$ may be interpreted as an accounting profit derived from a normal economic activity yielding a normal rate of return. Putting it differently, the RID takes account of the fact that investors 
could replicate the same pattern of cash flows up to time $T$; at time $T$, the investors would receive $F_{T}$ plus the terminal normal capital $b_{T}^{*}$, which is equal to

$$
b_{T}^{*}=F_{0} \cdot(\vec{r}), T-\sum_{t=1}^{T} F_{t} \cdot(\vec{r})_{, T}=-\mathrm{NPV} \cdot(\vec{r}), T=-\mathrm{NPV}_{T}
$$

The normal capital may be interpreted as the balance of a savings account which yields interest at the $\mathrm{NRP}$, and from which cash flows $F_{t}, t=1,2, \ldots, T$, are periodically withdrawn. The terminal normal capital is the terminal balance of the savings account and coincides with the project's accumulated NPV changed in sign: if the NPV is negative, then $b_{T}^{*} 0$, confirming that the investors profit from investing funds at the NRP; if the NPV is positive, then $b_{T}^{*} 0:$ that is, investors lose a negative terminal capital if they invest at the NRP, and, symmetrically, gain a terminal capital equal to the $\mathrm{NPV}_{T}$ if they invest in project $F$.

We henceforth use the term "residual income" to refer to the lost-capital RI defined in eq. (8), and interchangeably use the expression "normal capital", "unrecovered capital", and "lost capital" as synonymous expressions. The excess of actual capital over normal capital $\left(b_{t}-b_{t}^{*}\right)$ will be named "above-normal capital" or "abnormal capital" (it may be positive or negative, depending on the circumstances).

Remark 1.1. The RID stated above bears interesting relations to Egginton's (1995) Adjusted RI. In his work, the author defines residual income as $F_{t}-\operatorname{Dep}_{t}-r_{t} b_{t-1}$, where $\operatorname{Dep}_{t}=\operatorname{Dep}_{t}\left(b_{t-1}, t\right)=$ $b_{t-1}-b_{t}$ is the depreciation charge (note that $F_{t}-D e p_{t}=x_{t}$ ) He studies several kinds of depreciation schedules, among which he finds one that guarantees a constant residual income in each period (he calls it "maintainable RI"). To this end, he sets $\operatorname{Dep}_{t}\left(b_{t-1}, t\right)=F_{t}-r_{t} b_{t-1}$ or, explicitly $b_{t-1}-b_{t}=F_{t}-$ $r_{t} b_{t-1}$. Since $b_{0}=-F_{0}$, one finds $b_{t-1}=b_{t-1}^{*}$ (see eq. (7)). Therefore, Egginton's definition of book value depreciation implies the use of normal capital and the depreciation charge is $\operatorname{Dep}_{t}=\operatorname{Dep}_{t}\left(b_{t-1}^{*}, \quad \stackrel{*}{t}\right)=F_{t}-r_{t} b_{t-1}^{*}$. Now, the RID above may be found by subtracting any depreciation charge from $\operatorname{Dep}_{t}\left(b_{t-1}^{*},{ }_{t}^{*}\right)$. This is straightforward:

$$
\operatorname{Dep}_{t}\left(b_{t-1}^{*}, \quad \begin{array}{l}
* \\
)
\end{array}\right)-\operatorname{Dep}_{t}\left(b_{t-1}, t\right)=\left(F_{t}-r_{t} b_{t-1}^{*}\right)-\left(b_{t-1}-b_{t}\right)=x_{t}-r_{t} b_{t-1}^{*} \text {. }
$$

This makes RID take on an interesting accounting meaning: it is an excess depreciation charge that measures the asset's decline in value with respect to a normal (market-determined) depreciation. In other terms, it measures both depreciation through time and depreciation through use. While Scott (1953) observes that "economists cannot afford to lump together, as "depreciation", changes in present value caused by the passage of time, and by use" (p. 371), the lost-capital residual income just lumps them together (for this interpretation and relations with Keynes's, 1936, 1967, notion of user cost see Magni, 2009a, 2010a, 2016).

Note that RID defines the capital charge in a comprehensive way, that is, it includes both opportunity costs suffered by the owners of the asset: the opportunity of earning the normal rate of profit $i_{t}$ on the capital invested, and the opportunity of investing the normal capital $b_{t-1}^{*}$. It is useful to reshape RI to highlight the role of the comprehensive cost of capital, denoted by $\varrho_{t}$, which is a multiple of the normal rate of profit:

$\mathrm{RI}_{t}=x_{t}-\varrho_{t} b_{t-1}$ with $\varrho_{t}: r_{t} b_{t-1}^{*} /{ }_{t-1}$.

The cost of capital $\varrho_{t}$ (henceforth, often COC) is greater or smaller than the NRP depending on the relative weight of normal capital to book value. We may also write $\varrho_{t}: r_{t}+r_{t}\left(b_{t-1}^{*}-b_{t-1} / t_{t-1}\right.$ or, equivalently, $\varrho_{t}: r_{t}-r_{t}\left(b_{t-1}-b_{t-1}^{*} / t_{t-1}\right.$. This means that the capital charge consists of two opportunity costs. The first one relates to the NRP: for any euro of capital invested in the project in each 
period, investors forego $r_{t}$ euros. The second constituent relates to the normal capital that investor will own if they reject the project: investors sacrifice interest on the additional capital $\left(b_{t-1}^{*}-b_{t-1}\right)$ which they would own if they invested their funds at the NRP; however, should the abnormal capital be positive (i.e., $b_{t-1}-b_{t-1}^{*} 0$ ), investors would forego a negative opportunity cost (so that the cost of capital would be smaller than the NRP). The term $r_{t}\left(b_{t-1}-b_{t-1}^{*}\right)$ just reflects such a (positive or negative) cost.

It should be clear now that interest rate $r_{t}$ is an appropriate cost of capital sacrificed by the investors (a further confirmation will come from next sections' results). This COC enables one to link NPV and accounting measures in an elegant and fruitful way.

\section{Accounting Rates of Return, NPV and Capital Budgeting}

As a first result, we show that residual income as defined in (8)-(9) enjoys a striking property of additive coherence.

Proposition 2.1. The sum of residual incomes coincides with the project's time-T accumulated NPV, regardless of book values. Formally,

$$
\sum_{t=1}^{T} \mathrm{RI}_{t} \mathrm{~N} \quad \mathrm{PV} \cdot(\vec{r}), T \quad \mathrm{~N} \quad \mathrm{PV}_{T}
$$

Proof: From $a_{t} b_{t-1}=b_{t}-b_{t-1}+F_{t}$ and $r_{t} b_{t-1}=b_{t}^{*}-b_{t-1}^{*}+F_{t}$ one gets to

$$
\sum_{t=1}^{T} \mathrm{RI}_{t}=\sum_{t=1}^{T}\left(b_{t}-b_{t-1}-b_{t}^{*}+b_{t-1}^{*}\right)=-b_{0}+b_{T}+b_{0}^{*}-b_{T}^{*}
$$

The thesis is obtained noting that $b_{0}=b_{0}^{*}=-F_{0}, b_{T} \quad 0 \quad$ and $b_{T}^{*}=-\mathrm{NPV}_{T}$. $\square$ Proposition 2.1 implies that the NPV may be computed as

$\mathrm{NPV}=v(\vec{r}), \quad \sum_{t=1}^{T} \mathrm{RI}_{t}$.

Owing to eqs. (9)-(10) and the equality $x_{t}=a_{t} b_{t-1}$, one may reframe NPV as

$\mathrm{NPV}=v(\vec{r}), \quad \sum_{t=1}^{T} b_{t-1}\left(a_{t}-r_{t}\right)$.

Now, consider the right-hand side of (11) as a function $h$ of $\vec{a}=\left(a_{1}, 2, \ldots, T\right)$ for any fixed $\vec{r}=$ $\left(r_{1}, 2, \ldots, T\right)$ and $\vec{b}=\left(b_{1} b_{2}, \ldots, b_{T-1}\right)$ :

$$
h(\vec{a}):=v(\vec{r}),{ }_{T} \sum_{t=1}^{T} b_{t-1}\left(a_{t}-\varrho_{t}\right) .
$$

Applying the definition of Chisini mean with respect to function $h(\vec{a})$, the average ARR is obtained by searching for that constant accounting number $\bar{a}$ such that $h\left(a_{1}, 2, \ldots, a_{T}\right)=h(a, a \ldots, \bar{a})$ :

$v(\vec{r}), T \sum_{t=1}^{T} b_{t-1}\left(a_{t}-\varrho_{t}\right)=v(\vec{r}), \quad \sum_{t=1}^{T} b_{t-1}\left(\bar{a}-\varrho_{t}\right)$.

Given the linearity of the equation, the solution $\bar{a}$ of (12) exists and is unique:

$\bar{a}=\frac{\sum_{t=1}^{T} a_{t} b_{t-1}}{\sum_{t=1}^{T} b_{t-1}}=\frac{\sum_{t=1}^{T} x_{t}}{\sum_{t=1}^{T} b_{t-1}}$. 
It is noticeable that the Chisini mean found by imposing a zero NPV from the discounted-cash-flow function is the IRR; conversely, the Chisini mean extracted from the actual (possibly, nonero) NPV and framed in terms of lost-capital residual incomes is the average ARR (see Table 1). ${ }^{11}$ If we show that such an average ARR does not suffer problems a)-e), then it may well deserve the label of "economic yield". Note also that the average ARR associated with the lost-capital residual income is genuinely internal because it does not depend on external data such as NRP or normal capital.

TABLE 1

\section{CHISINI MEAN OF ACCOUNTING RATES ASSOCIATED WITH DIFFERENT FUNCTIONS}

\begin{tabular}{l|c|c}
\hline Function selected & Equation & Chisini mean of ARRs \\
\hline DCF function & $\left.-F_{0}+\sum_{t=1}^{T} F_{t} 1+i\right)^{-t} 0$ & IRR \\
\hline RI function & $\sum_{t=1}^{T} b_{t-1}\left(a_{t}-\varrho_{t}\right)=\sum_{t=1}^{T} b_{t-1}\left(\bar{a}-\varrho_{t}\right)$ & weighted average of ARRs \\
\hline \hline
\end{tabular}

Remark 2.1. The ARR is not defined if the book value is zero. However, the average ARR preserves its meaning, given that it does not depend on the book value of a single period: $\bar{a}=\frac{\sum_{t=1}^{T} x_{t}}{\sum_{t=1}^{T} b_{t-1}}$. The only requirement is that the sum $:=\sum_{t=1}^{T} b_{t-1}$ of the book values is nonzero (or, equivalently, that the average investment per period $\bar{b}$ : $S / T$ is nonzero). For a given cash-flow stream, this requirement may always be fulfilled, so the average ARR always exists (see end of Remark 3.1).

Like the average ARR, the weighted average $\bar{\varrho}$ of the costs of capital may be obtained as a Chisini mean by solving the equation $v(\vec{r}),{ }_{T} \sum_{t=1}^{T} b_{t-1}\left(a_{t}-\varrho_{t}\right)=v(\vec{r}){ }_{T} \sum_{t=1}^{T} b_{t-1}\left(a_{t}-\bar{\varrho}\right)$, which leads to

$$
\bar{\varrho}=\frac{\sum_{t=1}^{T} \varrho_{t} b_{t-1}}{\sum_{t=1}^{T} b_{t-1}} .
$$

This very solution is also obtained by searching for that ARR that makes the NPV equal to zero for any fixed $\vec{r}$ : from $h(\bar{a})=v(\vec{r}),{ }_{T} \sum_{t=1}^{T} b_{t-1}\left(\bar{a}-\varrho_{t}\right)=0$ one gets $\bar{a}=\frac{\sum_{t=1}^{T} \varrho_{t} b_{t-1}}{\sum_{t=1}^{T} b_{t-1}}=\bar{\varrho}$. This result is important: it tells us that whenever the average ARR is equal to the average COC, the resulting NPV is zero. Given that the choice of book values is immaterial, we have then proved the following result:

Proposition 2.2. For any book value depreciation, the NPV is zero if and only if the average ARR is equal to the average $\mathrm{COC}$.

Proposition 2.2. is more useful and reliable than the usual statement "the NPV is zero if and only if the IRR is equal to the normal rate of profit $r$ ", because the assumption of a constant cost of capital is 
unnecessary and the linearity of the equation serves as a powerful antidote against problems of existence and uniqueness.

Proposition 2.2 is promising. However, as Peasnell (1996) put it, "the yardstick is whether the difference between ARR and COC has the same sign as net present value (NPV)" (Peasnell, 1996, p. 296). This expectation is fulfilled, as it is now shown.

Theorem 2.1. For any book value depreciation, a project is worth undertaking if and only if the average $A A R$ is greater than the average COC. That is, $N P V>0$ if and only if $\bar{a}-\bar{\varrho} 0$. (If total book value is negative, the rule holds with $\bar{a}-\bar{\varrho} 0 \quad)^{12}$

Proof: Owing to (11), NPV $>0$ if and only if $\sum_{t=1}^{n} b_{t-1}\left(a_{t}-\varrho_{t}\right)=S(\bar{a}-\bar{\varrho} 0 \quad$, which means $\bar{a}>\bar{\varrho}$ if and only if $S>0$.

Theorem 2.1 confirms that to compare an (average) accounting rate with an appropriate cost of capital is not to compare oranges with apples. If investors undertake the project, they invest an overall capital equal to $S$ and earn a residual income equal to $(\bar{a}-\bar{\varrho})$ per unit of capital. The product structure $\cdot(\bar{a}-$ $\bar{\varrho})$ represents a scale-efficiency breakdown of the (time-t NPV): $S$ measures the scale (i.e., size) of the project while $(\bar{a}-\bar{\varrho})$ measures the project's economic efficiency. The scale-efficiency breakdown enjoys a residual-income structure, so that NPV is more conveniently interpreted as an excess return, namely the difference between project's total return and total normal return:

$$
\mathrm{NPV}_{T}=\sum_{t=1}^{n} x_{t}-\sum_{t=1}^{n} r_{t} b_{t-1}^{*}=\bar{a} S-\bar{\varrho} S .
$$

Remark 2.2 The ARR rule may also be reframed in terms of the weighted average of the NRPs. Letting $\bar{r}: \quad \frac{\sum_{t=1}^{T} r_{t} b_{t-1}}{\sum_{t=1}^{T} b_{t-1}}$, the rule becomes

$$
\bar{a}>\bar{r}-\bar{r} \cdot \frac{\sum_{t=1}^{T}\left(b_{t-1}-b_{t-1}^{*}\right)}{\sum_{t=1}^{T} b_{t-1}}=\bar{r} \frac{S^{*}}{S}
$$

where $S^{*}=\sum_{t=1}^{n} b_{t-1}^{*}$. The ratio $S^{*} /$ adjusts for scale, that is, it takes into account the fact that if investors invested funds at the NRP, starting with $b_{0}$ at time 0 , the overall invested capital would be $S^{*}$, not $S$. In other words, since $\bar{\varrho} S=\bar{r} S^{*}$, the investors forego to earn $\bar{r}$ on $S^{*}$, which is financially equivalent to invest $S$ at the rate $\bar{\varrho}$.

Note that every book value sequence univocally determines an average rate, but the reverse is not true. Rather, the average ARR is in a biunivocal correspondence with the total capital invested $S$ : the average ARR is a homographic function $\bar{a}(S)=\sum_{t=1}^{T} a_{t} b_{t-1} /$; likewise, the average COC is a homographic function of $S: \bar{J}(S)=\sum_{t=1}^{T} j_{t} b_{t-1} /$.

Profitability does not depend on return rates per se, but on relations between (or among) return rates; it is not economic yield per se which is relevant, but the difference between the economic yield and the cost of capital. In particular, it is the ARR margin $(\bar{a}-\bar{\varrho})$ that counts. And the sign of the latter is actually invariant under changes in book value, as it is now shown.

Proposition 2.3. Given the total capital invested, the ARR margin is either positive or negative, regardless of book values.

Proof: Consider the average ARR and the average COC as functions of book values: $\bar{a}=\bar{a}\left(b_{1}, \ldots, T-1\right)$ and $\bar{\varrho}=\bar{\varrho}\left(b_{1}, \ldots, T-1\right)$. Using the equalities $b_{t}^{*}=-\sum_{k=0}^{t} F_{k} u(\vec{r}), t$ and $x_{t}=F_{t}-\left(b_{t}-b_{t-1}\right)$, $=$ $1, \ldots, T$, 


$$
\begin{gathered}
\bar{a}\left(b_{1}, \ldots, T-1\right)-\bar{\varrho}\left(b_{1}, \ldots, b_{T-1}\right)=\frac{\sum_{t=1}^{T}\left(x_{t}-r_{t} b_{t-1}^{*}\right)}{S}=\frac{F_{0}+\sum_{t=1}^{T}\left(F_{t}-r_{t} b_{t-1}^{*}\right)}{S} \\
=\frac{\sum_{t=0}^{T} F_{t}+\sum_{t=1}^{T}\left[r_{t} \sum_{k=0}^{t-1} F_{k} u(\vec{r}), t-1\right]}{S} .
\end{gathered}
$$

For any given $S$, the sign of the ratio depends on the sign of the numerator, which is independent of book values.

The fact that the average ARR and the average COC do not depend on book values but on the sum of all book values enables one to part all possible depreciation schedules into depreciation classes. Denote with $B_{S}=\left\{\vec{b} \in{ }^{T-1}: \sum_{t=1}^{T} b_{t-1}=S\right\}$ the class of those depreciation patterns that share the same grand total investment $S$. We say that two depreciation patterns are equivalent if they belong to the same depreciation class. The sets $B_{S}, \in \mathbb{R}$, are then equivalence classes and constitute a partition of the union set $\cup_{\in \mathbb{R}} B_{S}$, which is the set of all possible depreciation patterns $\vec{b}$. To every equivalence class $B_{S}, \in$ $\mathbb{R}-\{0\}$, there corresponds an average ARR, namely $\bar{a}(S)=\sum_{t=1}^{T} x_{t-1} /$. If two depreciation schedules are equivalent, they share the same average ARR. A class of depreciation patterns which are equivalent to a Hotelling depreciation schedule will be named "Hotelling class". The class $B_{S^{*}}$ such that $S^{*}:=$ $\sum_{t=1}^{T} b_{t-1}^{*}$ will be named "normal class". We will also use the notion of discounted depreciation class, which is the set $D B_{Q}=\left\{\vec{b} \in{ }^{T-1}: v(\vec{r}), \quad \cdot \sum_{t=1}^{T} b_{t-1}=Q\right\}$ of those depreciation schedules that share the same discounted total capital $Q$.

The variability of the average ARR and COC with respect to $S$ is an advantage. Any project may actually be described as an investment of any capital $S$ for $T$ periods at the $T$-period internal return rate $\bar{a}(S)$. Changing $S$, the project is described as the investment of a different capital: the average ARR and the average COC adjust accordingly, just in order to maintain the NPV unchanged (remember the definition of Chisini mean). This is the reason why the ARR rule is unfailing: its flexibility allows for different representations of the same phenomenon, but the different representation leads to the same evaluation and the same decision. In actual fact, the economic analysis does not depend on one rate or on the capital invested, but on the joint effect of the triplet $(a \bar{Q}, \quad)$ : average ARR, average COC, and total capital invested. It is this triplet that jointly determines the NPV. Geometrically, the triplet is individuated by the intersection of the straight line passing through $S$ with the graphs of the average ARR and COC functions (see Figure 1, which depicts a positive NPV asset such that $\sum_{t=1}^{T} x_{t-1}>\sum_{t=1}^{T} r_{t} b_{t-1}^{*} 0 \quad$ ). Every straight line which is parallel to the vertical axis corresponds to a depreciation class and univocally determines a triplet: any such triplet leads to the same NPV. This implies that, for any bundle of projects, one may describe the projects as if they were equal-capital investments, even if the outlays are actually different (see also Remark 3.1 below); and this in turn offers one the opportunity of using the ARR rule for ranking projects. To this end, note that the IRR ranking is based on the (fallacious) principle of maximization of the IRR or, which is the same, on the maximization of the IRR margin $(i-r)$. We now show that, on the contrary, the correct investment policy is: maximize the ARR margin $(\bar{a}-\bar{\varrho})$. We begin with a lemma which shows that, given any bundle of projects with fixed cash flows, one may choose depreciation patterns such that the total capital invested is the same for all projects. 


\section{FIGURE 1}

\section{ANY TRIPLET $(S, \bar{a}(S),-(S))$ UNIVOCALLY DETERMINES THE TIME-T ACCUMULATED NPV}

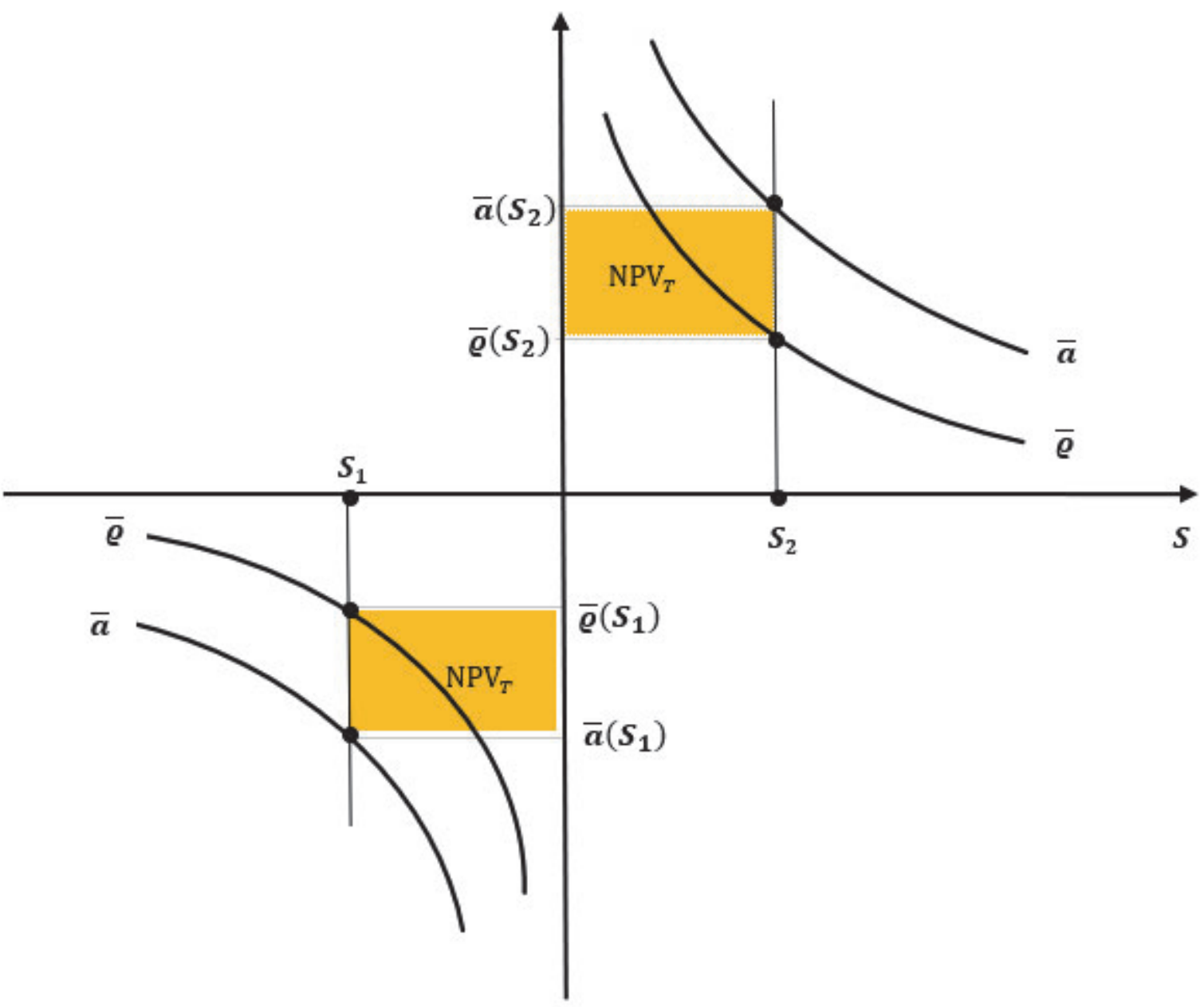

Lemma 2.1. For any set of projects, there exist infinite depreciation patterns such that all projects belongto the same depreciation class and there exist infinite depreciation patterns such that all projects belong to the same discounted depreciation class.

Proof: Consider $K$ projects. Project $k$ 's length is $T_{k}, \quad=1,2, \ldots K$. Let $b, k$ be the time- $t$ book value of project $k$ and consider, for any fixed $S \neq 0$, the system $\sum_{t=1}^{T_{k}} b_{t-1, k}=S, k=1,2, \ldots, K$, of $K$ equations with $T_{1}+T_{2} \cdots+T_{K}-K$ unknowns (initial book values are known). Evidently, the system has infinite solutions, so the first part of the lemma is proved. As for the second part, the proof is analogous by picking any $Q \neq 0$ and considering the system $v(\vec{r}), \quad k \cdot \sum_{t=1}^{T_{k}} b_{t-1, k}=Q, k=1,2, \ldots, K$.

Theorem 2.2. Ranking projects with the ARR margin is equivalent to ranking projects with the NPV, provided that the same depreciation class (or discounted depreciation class for unequal-life projects) is chosen for all projects.

Proof: Consider $K$ projects. Let $\vec{b}_{k}$ be the depreciation plan for project $k$ and NPV ${ }^{k}$ be project $k$ 's NPV. Project $k$ 's length is $T_{k},=1,2, \ldots$. First, suppose the projects have equal life. Then, pick any real 
number $S \neq 0$ and $K$ depreciation patterns such that, $\vec{b}_{k} \in{ }_{s}$ for all $k=1,2, \ldots, K$ (its existence is guaranteed by Lemma 2.1). Given any pair of projects $p$ and $h$, we have $T_{p}=T_{h}$ by assumption. Then, $\mathrm{NPV}^{p}>\mathrm{NPV}^{h}$ if and only if $S\left(\bar{a}_{p}-\bar{\varrho}_{p}\right)>S\left(\bar{a}_{h}-\bar{\varrho}_{h}\right)$. The thesis follows by dividing by $S$. Now, suppose the projects have unequal life and pick any real number $Q \neq 0$. By Lemma 2.1, there exist infinite depreciation patterns such that the discounted total capital is $Q$ for all projects. Therefore, $\mathrm{NPV}^{p}>\mathrm{NPV}^{h}$ if and only if $Q\left(\bar{a}_{p}-\bar{\varrho}_{p}\right)>Q\left(\bar{a}_{h}-\bar{\varrho}_{h}\right)$, that is, $\bar{a}_{p}-\bar{\varrho}_{p}>\bar{a}_{h}-\bar{\varrho}_{h}$.

In other words, the correct investment policy is not "maximize the IRR margin", but "maximize the ARR margin". ${ }^{13}$ To reach this result, one only needs choose the same depreciation class (or discounted depreciation class) for all projects. The corresponding average rates provide the correct results (see, on this point, Remark 3.1 below).

\section{Average ARR, IRR and Economic Yield}

In section 1 we have shown that the traditional IRR may be seen as the Chisini mean of the accounting rates associated with the discounted-cash-flow function. Thanks to the notion of depreciation class, we are now able to show that the traditional IRR is just one among many infinite average ARRs associated with the RI function $g\left(a_{1}, 2, \ldots{ }_{T}\right): \quad \sum_{t=1}^{T} b_{t-1}\left(a_{t}-\varrho_{t}\right)$.

Theorem 3.1. Suppose an IRR exists. Then, that IRR is the average ARR of a Hotelling class.

Proof: Let $\vec{h}$ be the vector of Hotelling book values (i.e., $h_{t}=h_{t-1}(1 \quad)-F_{t}$ ); we have $\vec{h} \in{ }_{H}$ for some $\in \mathbb{R}-\{0\}$. Let $\vec{b} \in{ }_{H}$. Then, the average ARR associated with the residual income function $g\left(a_{1}, 2, \ldots, T\right)=\sum_{t=1}^{T} b_{t-1}\left(a_{t}-\varrho_{t}\right)$ and corresponding to $B_{H}$ is $\bar{a}(H)=\sum_{t=1}^{T} a_{t} b_{t-1} /$. Also, $\sum_{t=1}^{T} a_{t} b_{t-1}=\sum_{t=1}^{T} x_{t}=\sum_{t=0}^{T} F_{t}$ for any $\vec{b}$. Hence, $\sum_{t=1}^{T} a_{t} b_{t-1}=\sum_{t=1}^{T} i h_{t-1}$, which means $\bar{a}(H)=$ $\sum_{t=1}^{T} i h_{t-1} /=\sum_{t=1}^{T} i h_{t-1} / \sum_{t=1}^{T} h_{t-1}=i .^{14}$

Theorem 3.1 shows that an IRR is (not a constant rate of return) but an average ARR associated with one equivalence class among many infinite classes that exhaust the union set $\bigcup_{\in} \mathbb{R} B_{S}$ of all possible depreciation patterns. ${ }^{15}$ If multiple IRRs exist, there are as many Hotelling classes as the number of the IRRs: to each Hotelling class there corresponds an IRR. Equivalent depreciation patterns describe a project in the same way: same total capital invested, same average ARR, same average COC. The IRR is then not univocally associated to a Hotelling depreciation schedule, but to a Hotelling class: many infinite depreciation schedules belong to that class. The fact that the IRR is drawn from an equation where book values do not appear conceals the fact that the evaluator is choosing the depreciation class $B_{H}$ among infinite depreciation classes. In other words, the IRR is an average ARR which is invariant under changes in book value only as long as a depreciation pattern contained in the Hotelling class is selected. Hotelling class and IRR are inextricably chained each other:

the IRR has its own built-in capital recovery pattern ... The "true yield" does not change because it cannot be adjusted away from its own built-in capital recovery formula" (Vatter, 1966, p. 683, footnote 3).

More precisely, the IRR depends on its own built-in capital recovery class. To choose the IRR as an average ARR does not mean to choose a precise depreciation schedule, but only a class; this entails that the IRR is an average ARR corresponding to infinite depreciation schedules belonging to the same class. (Theorem 3.1 is just the proof of this stance, which is exactly Vatter's, 1966, stance). It is worth underlining that if a Hotelling class does not exist, it does not obviously mean that the average ARR does not exist. It only means that none of the depreciation classes contained in $\bigcup_{\in} \mathbb{R}_{S}$ includes any depreciation schedule generating a sequence of constant accounting rates. 
To choose the IRR as the "true" yield boils down to choosing Hotelling class as the "true" depreciation class. But why should a Hotelling class be economically more significant than any other class? Should economic profitability depend on a particular depreciation class? If the answer is no, then one should not accept a Hotelling class (nor any other one) as the true economic depreciation class. If the answer is yes, then why should economic profitability depend on something slippery that may not even exist or may be multiple? Any other average ARR is as true as the IRR. The IRR is, formally, just the image of the function $\bar{a}(S)$ for $S=H$.

Actually, there is no true yield and there is no true depreciation: "unless capital recovery process is specified, there is no single way to measure the annual productivity of the investment" (Vatter, 1966, p. 687). The problem of deriving the "true" book value sequence $\vec{b}$ is equivalent to a well-known issue in the philosophy of science: the so-called underdetermination of theory by data (see Duhem, 1914; Schlick, 1931; Quine, 1951). Given a sequence of empirical data, there are many infinite functions that exactly pass through those points (Schlick, 1931). That is, the scientific law is underdetermined by data. In this respect, we may only observe two economic data: at time 0 , the capital invested is $b_{0}=-F_{0}$ and, at time $T$, when the project is over, the capital is $b_{T} 0$; but, given two points $\left.0, b_{0}\right)$ and $(T, 0)$ on the $\left(t, b_{t}\right)$ plane, any depreciation schedule is a function that passes through those two points: the book value function is undetermined by the economic data (see Figure 2). It is arbitrary to say that one of these functions is true and economic (Hotelling book value function), while the other ones are false and accounting. Considering that Hotelling class and the corresponding IRR produce a plethora of problems (problems a)-e) above), why should a Hotelling class (or even a Hotelling depreciation schedule) be superior to any other depreciation class? And if one declares that a Hotelling depreciation schedule guarantees constant accounting rates, why should constant accounting rates be more "economic" than, say, constant depreciation charges? Above all, in capital budgeting, accounting incomes (and, therefore, book rates of return) are first-order variables: cash flows are second-order variables because they depend on prospective incomes and book values rates. Since the IRR depends on forecasted cash flows, and cash flows depend on forecasted accounting rates, the IRR depends on the accounting rates as well (see Remark 3.1). Then, why should the IRR be considered economic as opposed to the very accounting rates which generate it?

Underdetermination is inevitable; but it should not trigger vain attempts to find the economic truth; we have a powerful tool for overcoming underdetermination: the Chisini mean of the accounting rates associated with the (lost-capital) RI function. Thanks to the latter, any depreciation method one uses for measuring the economic profitability of a project will work, as long as the appropriate cost of capital is put into play. 


\section{FIGURE 2}

UNDERDETERMINATION OF THE BOOK VALUE FUNCTION BY THE ECONOMIC DATA (THE FUNCTIONS ARE CONTINUOUS FOR ILLUSTRATIVE PURPOSES)

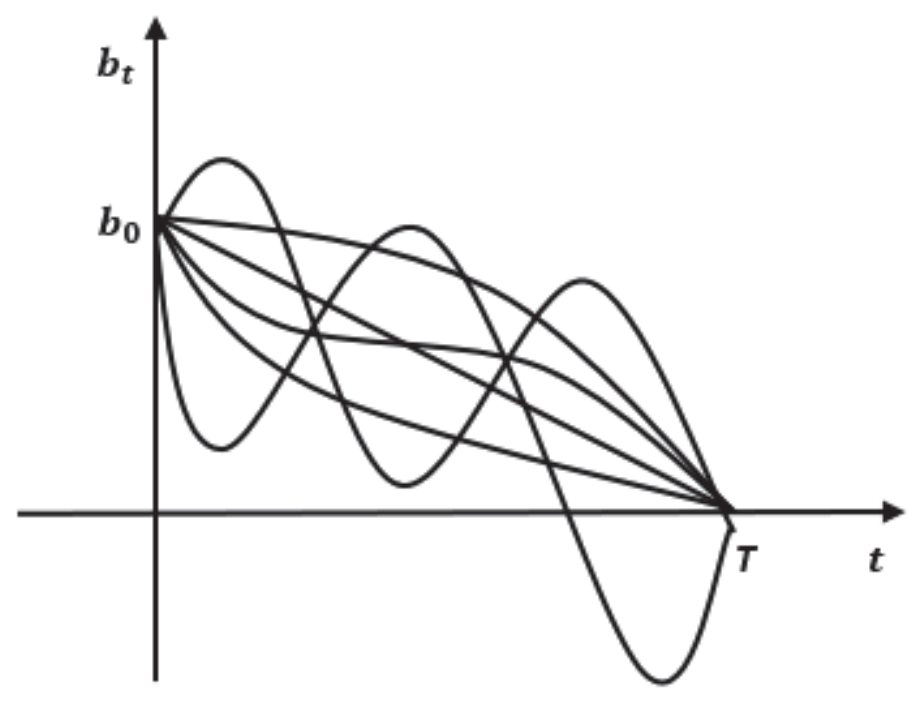

Remark 3.1. One should not confuse the way cash flows are forecasted in a capital budgeting exercise and the use of the average ARR for the capital budgeting decision. Cash flows may be forecasted in several different ways. One way is to forecast income and determine book value depreciation, which is essentially given, in an equity perspective, by change in working capital plus change in net fixed assets minus change in debt; the clean surplus relation (law of motion) is then used for unravelling the cash flows: $t_{t}=x_{t}-$ $\left(b_{t}-b_{t-1}\right)$. In this sense, "accounting variables, are the 'independent' variables and net dividends the 'dependent' variable, not the other way around" (Brief, 1996, p. 28) Once computed the expected cash flows, economic profitability is correctly revealed by the sign of the ARR margin, whatever the book value function. Now, suppose project or firm ranking is at issue: one just reframes depreciation patterns so as to guarantee that the depreciation class is the same for all projects: the resulting ARR margins will correctly rank the projects (with a spreadsheet the entire procedure is automatic). It is extremely important to underline the fact that the evaluator who extracts an IRR from the discounted-cash-flow equation cannot dodge and sidestep reframing of the depreciation pattern: precisely because an IRR corresponds to a Hotelling class, the evaluator solving the usual discounted-cash-flow equation changes, ipso facto, the original depreciation class (the one which has been used for unravelling cash flows) into a Hotelling depreciation class. So, the very question "why should one compute an average ARR if one already knows the cash flows, given that one can directly compute the IRR?" is mis-raised, because anyone who computes an IRR is himself (implicitly) choosing a depreciation plan within Hotelling class and computing the corresponding average ARR. There is no way of escaping accounting. ${ }^{16}$

If one is willing to rank projects, the correct ranking may be made via the ARR margin. So, once the financial analyst has forecasted cash flows, he will necessarily choose any preferred depreciation class and make use of the ARR rule, if he is willing to draw return rates. And given that one can choose any depreciation class, one may always avoid the zero-depreciation class $(S=0)$, so that the average ARR is well-defined. ${ }^{17}$

Remark 3.2. The empirical research literature "generally accepts that economic performance is the IRR being earned by the firm" (Stark, 2004, p. 322) and, given the problems in determining cash flows (and thus the IRR), the search for a reliable proxy of the IRR is investigated. In particular, scholars and analysts are concerned with finding relations between annual ARR and ex post IRR, or between average ARR and ex post IRR, or between average ARR and ex ante IRR (see a review of this literature in Feenstra and Wang, 2000. See also Luckett, 1984). The underlying idea is to search "for insight into the 
usefulness of an accounting time-series for a limited time segment as an indicator of multi-period economic performance." (Peasnell, 1996, p. 293). In the light of what we have seen, one may say that the purpose expressed in the latter sentence should not inspire the question "to what extent an annual or an average ARR for a limited time segment is a proxy for the IRR?" but, more properly, the question "to what extent an average ARR for a limited time segment is a proxy for an overall average ARR?". With two cautions: (i) monopoly rents are realized if economic performance $\bar{a}$ is greater than the cost of capital $\bar{\varrho}$, not the NRP, (ii) ranking of projects/firms should be made with the ARR margin, not with the ARR itself (let alone the IRR), barring the exceptional case of Proposition 3.3 below.

As a result, the theoretical status of the average ARR should be boosted, whereas the status of the IRR should be diminished. Nevertheless, the latter may well be employed, just because it is a genuine average ARR (if it exists). The correct use of the IRR is as follows.

Proposition 3.1 Suppose an IRR exists. Then, the project is worth undertaking if and only if that IRR is greater than the average corresponding COC: $i-\bar{\varrho}(H)>0$, with $:=\sum_{t=1}^{T} h_{t-1}$, (if $H<0$, the sign is reversed).

Proof: The proof is trivial, given Theorem 2.1 and given that, by Theorem 3.1, $i=\bar{a}(H)$.

FIGURE 3 MULTIPLE IRRS: EACH IRR IS CONTRASTED WITH THE CORRESPONDING AVERAGE
COC, PROVIDING THE SAME SOLUTION

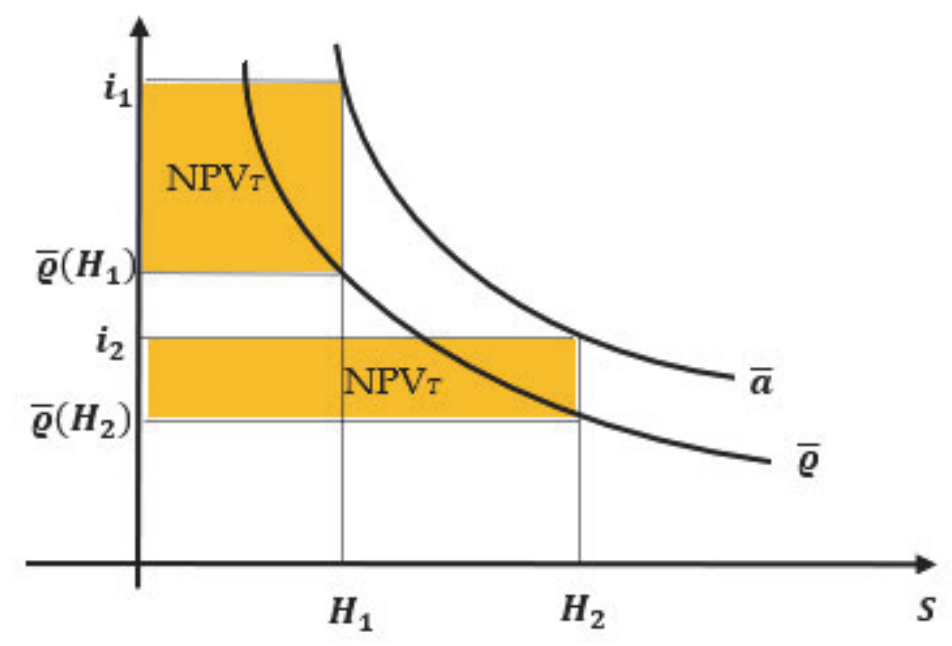

Proposition 3.1 wipes out problems b)-e) related to the IRR (Figure 3). In particular, in case of multiple IRRs, each IRR may be contrasted with its own corresponding average COC: the answer on profitability will be the same. The proposition confirms again that $\bar{\varrho}$ is a correct cost of capital, not the NRP. However, suppose a depreciation plan is selected belonging to the normal class: $\sum_{t=1}^{T} b_{t-1}=\sum_{t=1}^{T} b_{t-1}^{*}$. This implies that the average COC is obtained by weighting NRPs by the lost, unrecovered capitals: $\bar{\varrho}=\sum_{t=1}^{T} r_{t} b_{t-1}^{*} / \sum_{t=1}^{T} b_{t-1}^{*}$. If, in addition, $r_{t}=r$ for all $t$, then $\bar{\varrho}=r$ and the average ARR is soundly contrasted with the NRP. Therefore, reminding Theorem 2.1, the following result holds (see Figure 4).

Proposition 3.2. If the depreciation class for the project is the normal class, the average COC is obtained by weighting the normal rates of profit by the unrecovered capitals. If, in addition, the normal rate of profit is constant, the COC equals the NRP and a project is worth undertaking if and only if the average ARR is greater than the normal rate of profit: $\bar{a}\left(S^{*}\right)-r>0$ (if $S^{*} 0$, the sign is reversed). 
To sum up: if the evaluator considers Hotelling class as particularly relevant to his ends, he may use any IRR he may find, as long as it is contrasted with the corresponding average COC. And, symmetrically, if the evaluator considers the normal depreciation class particularly relevant to his ends, he may well use the normal class, as long as he contrasts the normal rate of profit with the corresponding average ARR. ${ }^{18}$

\section{FIGURE 4 \\ THE NORMAL RATE OF PROFIT (AVERAGE COC CORRESPONDING TO THE NORMAL DEPRECIATION CLASS) IS CONTRASTED WITH THE CORRESPONDING AVERAGE ARR}

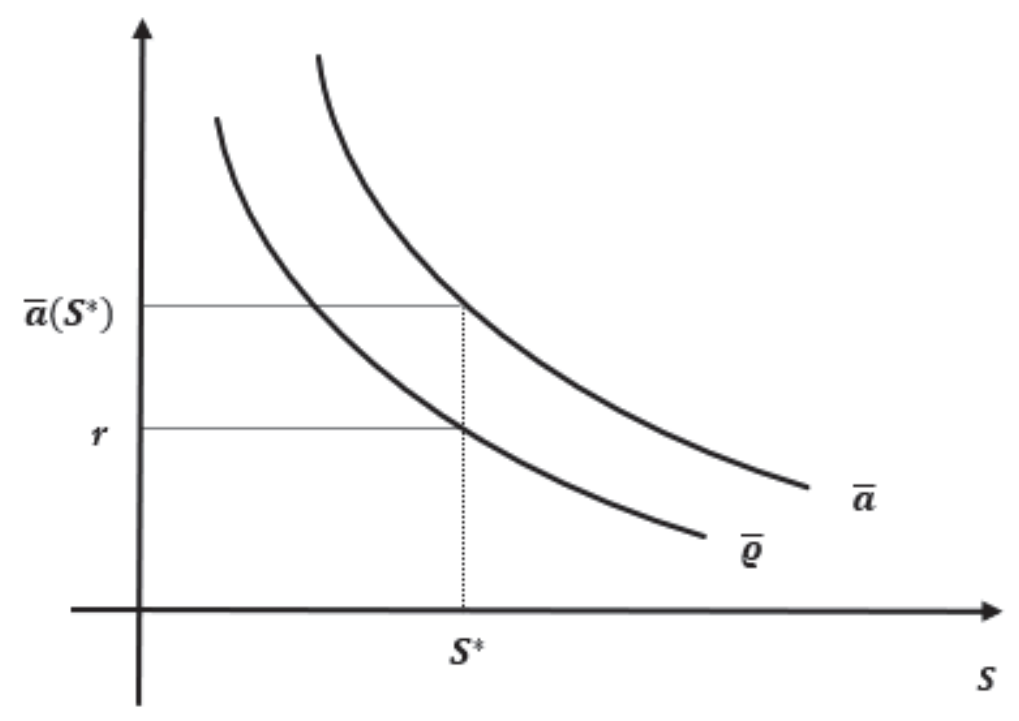

Proposition 3.2 enables one to state sufficient conditions under which project ranking may be accomplished by ranking the ARRs alone.

Proposition 3.3. Assume the NRP is constant. If $K$ projects share the same total lost capital $S^{*}$ : $\sum_{t=1}^{T} b_{t-1}^{*}$, then, project ranking with the ARR is equivalent to NPV ranking, provided that the total book value (or discounted total book value if projects have different lengths) is the same for all projects and equal to the total lost capital.

Proof: Suppose the projects have equal life. Then, if all projects share the same total lost capital $S^{*}$, and if the depreciation classes are chosen so that $S=S^{*}$ for all projects, then, by Proposition 3.2, the average COC is equal to the NRP for all projects. Hence, by Theorem 2.2, contrasting NPV ${ }^{p}$ with $\mathrm{NPV}^{h}$ is equivalent to contrasting $\left(\bar{a}_{p}-r\right)$ with $\left(\bar{a}_{h}-r\right)$, which is in turn equivalent to contrasting $\bar{a}_{p}$ with $\bar{a}_{h}$. Analogously for projects of unequal lives, with the caveat that the discounted total capital must replace total capital.

Just because of the flexibility of the triplet $(S, a \bar{\varrho})$, one may well choose $b_{t}=b_{0}$ for all $t<T$. Hence, the weighted average ARR (respectively, COC) coincides with the arithmetic mean of ARRs (respectively, COCs):

$$
\bar{a}=\frac{\sum_{t=1}^{T} a_{t} b_{0}}{T b_{0}}=\frac{1}{T} \sum_{t=1}^{T} a_{t}, \quad \bar{\varrho}=\frac{\sum_{t=1}^{T} \varrho_{t} b_{0}}{T b_{0}}=\frac{1}{T} \sum_{t=1}^{T} \varrho_{t}
$$


Thus, by Theorem 2.1, one finds the following

Theorem 3.2. If the book value function is constant for $t<T$, the simple and weighted average ARR coincide. A project is worth undertaking if and only if the simple arithmetic mean of ARRs is greater than the simple arithmetic mean of COCs.

Corollary 3.1. Suppose $C$ is a fixed-income asset, with cash-flow vector $\left(-b_{0}, b_{0}, b_{0} \ldots, b_{0}+b_{0}\right)$. If a Hotelling class is selected, weighted average ARR, simple average ARR, and IRR coincide.

Proof: It is easily checked that $\mathrm{NPV}(i)=0$ and the asset is a Soper project, so $i$ is the unique IRR. Hotelling book value is $h_{t}=b_{0}$ all $t<T$, so that Theorem 3.2's assumptions are met. The latter theorem and Theorem 3.1 imply the thesis.

Corollary 3.2. The simple average ARR corresponding to a constant book value function is equal to the weighted average ARR corresponding to class $B_{T b_{0}}$.

Proof: Let $\vec{b} \in T b_{0}$ and let $a_{t}(\vec{b})$ the corresponding ARR. We have, for every $\vec{b} \in T b_{0}, \bar{a}\left(T b_{0}\right)=$ $\sum_{t=1}^{T} a_{t}(\vec{b}) b_{t-1} / \sum_{t=1}^{T} b_{t-1}$. In particular, consider $y \in B_{T b_{0}}$ such that $y_{t}=b_{0}$ for all $t<T$; then, by Theorem 3.2, $\bar{a}\left(T b_{0}\right)=\frac{1}{T} \sum_{t=1}^{T} a_{t}(\vec{y})$.

To sum up: the economic yield is the weighted average of the ARRs, and the IRR is only an average ARR corresponding to one depreciation class (Hotelling). A correct cost of capital is the weighted average of the comprehensive COCs, and the NRP is only one average COC corresponding to one depreciation class (normal). To focus on the IRR as the economic yield unaffected by depreciation is like using a microscope in order to make extremely small (or inexistent) things look larger.

Definition 3.1 For any book value depreciation, the economic yield of a project is the arithmetic mean of the ARRs, either simple or weighted by book values.

Given that the ARR function exists for any project and is uniquely associated with it, one may equivalently state the following

Definition 3.2 For any project, the economic yield is the ARR function associated with the project.

The unfailingness of the ARR margin makes it a reliable substitute of the NPV for decision-making. A question is now naturally raised: is residual income a reliable substitute of the NPV as well? The answer is given in section 4 .

\section{Residual Income, NPV and Capital Budgeting}

Project $F$ 's accumulated NPV may be written as $\operatorname{NPV}_{T}=T \bar{b}(\bar{a}-\bar{\varrho})$, with $\bar{b}=S / T$; that is, the project generates, on average, a residual income equal to $\bar{b}(\bar{a}-\bar{\varrho})$ for $T$ periods. It is worth noting that such a residual income is a simple arithmetic mean of project $F$ 's residual incomes:

$\bar{b}(\bar{a}-\bar{\varrho})=\frac{\sum_{t=1}^{T}\left(x_{t}-\varrho_{t} b_{t-1}\right)}{T}=\frac{\sum_{t=1}^{T} \mathrm{RI}_{t}}{T}$.

Let $\overline{\mathrm{RI}}$ denote the simple arithmetic mean of residual incomes. ${ }^{19}$ From the proof of Proposition 2.3, eq. (14) becomes 


$$
\overline{\mathrm{RI}}=\frac{\sum_{t=0}^{T} F_{t}+\sum_{t=1}^{T}\left[r_{t} \sum_{k=0}^{t-1} F_{k} u(\vec{r}), t-1\right]}{T} .
$$

and the derivative $\frac{\partial \overline{\mathrm{RI}}}{\partial b_{t}}$ is identically zero for every $t$. Hence, $\overline{\mathrm{RI}}$ is invariant under changes in book values; in particular, it is constant regardless of whether the asset is depicted as an investment $(S>0)$ or as a financing $(S<0)$ (just because it is the product of $/ T$ and $\bar{a}-\vec{\jmath}$ ).

Proposition 4.1. A project is worth undertaking if and only if $\overline{R I} 0$, whatever the book value depreciation.

Proof: NPV $>0$ if and only if $\bar{a}>\bar{\varrho}$ and $S>0$ or $\bar{a}<\bar{\varrho}$ and $S<0$ (by Theorem 2.1), which is equivalent to $\left(\frac{S}{T}\right)(\bar{a}-\bar{\varrho})=\bar{b}(\bar{a}-\bar{\varrho}) \mathrm{R} \overline{\mathrm{I}} 0$, regardless of the asset base.

Proposition 4.1 is important because it opens the way to a biunivocal relation between NPV and residual income. Formally, the RI rule just stated is equivalent to the NPV rule: the investor needs only look at the sign of an index, be it the NPV or the average RI: if it positive, project is profitable; if it zero, project is value-neutral; if it is negative, project is not profitable. (Average) residual income is then a perfect accounting substitute of the NPV rule for accept/reject decisions.

Average RI, ARR margin and NPV are just the same concept expressed in terms of excess profit, excess return rate, and excess capital value, ${ }^{20}$ respectively. What about ranking projects? The answer lies in the following equality:

$\mathrm{NPV}=v(\vec{r}),{ }_{T} \sum_{t=1}^{T} \mathrm{RI}_{t}=\alpha(T) \bar{b}(\bar{a}-\bar{\varrho})=\alpha(T) \cdot \overline{\mathrm{RI}}$

where $\alpha(T):=\cdot v(\vec{r}),{ }_{T}$. We first assume that projects have equal lives.

Theorem 4.1. Assume $K$ projects share the same lifespan. Then, maximization of the average RI is equivalent to maximization of $N P V$, regardless of book value depreciation.

Proof: Let $K$ be the number of projects, denoted by $k=1,2, \ldots, K$ and let $T$ be the lifespan shared by all projects. By eq. (15), $\max _{1 \leq k \leq K} \mathrm{NPV}^{k} \operatorname{m}_{1 \leq k \leq K} \underset{\operatorname{ax}}{\alpha} \alpha(T) \cdot \overline{\mathrm{RI}}^{k} \quad \operatorname{m}_{1 \leq k \leq K} \underset{\mathrm{RI}}{ }{ }^{k}$, where $\overline{\mathrm{RI}}^{k}$ is project $k$ 's average RI.

The term $\alpha(T)$ is a weight imposed on the project's average RI and is equal to the market value of $T$ euros available at time $T$. This implies that the NPV may be interpreted as an average RI weighted by the market value of the project's length. Intuitively: economic profitability does depend on (average) residual income, but it also depends on how long residual income will be generated by the project.

Dealing with projects of unequal life, we may not compare the average RI as such, because some projects may generate smaller average RIs for longer periods. Let $T_{k}$ be the lifespan of project $k=1,2, \ldots$, $K$ and let $\mathrm{Z} \mathrm{m}$ ax $\left[T_{1}, 2, \ldots,{ }_{K}\right]$ be the maximum length; weighting project $k$ 's average RI with the relative length $\left(T_{k} /\right)$ and considering its future value at time $Z$, we introduce the project $k$ 's time-scaled RI

$$
\mathrm{TRI}^{k} \mathrm{R} \overline{\mathrm{I}}^{k} \cdot \frac{T_{k}}{Z} \cdot(\vec{r})_{T_{k}}
$$

which is just the time- $Z$ accumulated NPV averaged out across $Z$ periods.

Note that $\sum_{t=1}^{Z} \mathrm{TRI}^{k}=Z \cdot \mathrm{TRI}^{k} \mathrm{R} \overline{\mathrm{I}}^{k} \cdot{ }_{k} \cdot(\vec{r})_{T_{k}}=\mathrm{NPV}^{k} \cdot(\vec{r}), z \cdot$ In this way, the additive coherence property of residual income is fulfilled (see Proposition 2.1). Also, 


$$
\max _{1 \leq k \leq K} \mathrm{NPV}^{k} \operatorname{m}_{1 \leq k \leq K} \operatorname{ax}_{1} Z \cdot \mathrm{TRI}^{k} \quad \operatorname{m}_{1 \leq k \leq K} \operatorname{aRI}^{k}
$$

We have then proved the following

Theorem 4.2. Given a set of projects with different lives, maximization of the time-scaled RI is equivalent to NPV maximization, whatever the book values.

To better appreciate the time-scaled RI, we remind Egginton's (1995) contribution, where a notion of periodic consistency is invoked; according to the author, if a RI metric is to be a legitimate tool (for capital budgeting and) for performance appraisal and control, it must enjoy two requirements: (A) ex ante RIs should reflect the NPV ranking between different projects, so that if project $p$ 's NPV is greater than project $h$ 's, the ex ante RIs of project $p$ exceeds those of project $h$ in every period; (B) the ex ante RI sequence should be constant or increasing, to prevent manager from adopting less profitable projects with good early rewards. The author finds a (standard) RI that fulfills both requirements, but only for projects of equal life (he calls it maintainable RI). Theorem 4.2 allows us to state that the time-scaled RI enjoys both Egginton's requirements (even for projects of unequal life), regardless of the asset base.

Consider now project $k$ whose length is $T_{k}$. We impose that the average above-normal capital per period be constant over time: $\left(b_{t}-b_{t}^{*} /=M\right.$ for all $1 \leq T_{k}$. This implies that the book value is $b_{t}=b_{t}^{*}+t M$. Using AI, residual income of project $k$ is

$$
\mathrm{RI}_{t}^{k}=b_{t}-b_{t-1}-\left(b_{t}^{*}-b_{t-1}^{*}\right)=t M-(t-1) M=M \quad \text { for all } 1 \quad \leq T_{k} .
$$

Therefore, $M$ is a "maintainable" RI, to use Egginton's (1995) words. A question arises: which relation do the average RI and the maintainable RI bear each other? The answer lies in the following equality:

$M=\frac{\mathrm{NPV}^{k} \cdot(\vec{r}), \quad k}{T_{k}}=\frac{\sum_{t=1}^{T_{k}} \mathrm{RI}_{t}^{k}}{T_{k}} \mathrm{R} \overline{\mathrm{I}}^{k}$

Maintainable RI is equal to average RI (it is worth reminding that the left-hand side depends on book value, whereas the right-hand side does not).

If one scales maintainable RI for time, as previously done for the average RI, one transforms unequallife projects into equal-life projects, so that residual income is generated over $\mathrm{Z}$ periods. We then state the following

Proposition 4.2. For any book value depreciation, the simple arithmetic mean of residual incomes is equal to the maintainable RI. The time-scaled RI is then interpretable as a time-scaled simple arithmetic mean of any RI sequence or, equivalently, as the maintainable RI sequence distributed over a common horizon. Owing to Theorem 4.1 and Theorem 4.2, maintainable RI ranking reflects NPV ranking.

With the time-scaled RI (derived from either the maintainable RI or the average of any RI sequence), it is as if all projects shared the same length. In such a way, the project may be interpreted as generating constant residual incomes for $\mathrm{Z}$ periods. The length of a project is actually conventional: one may consider project $k$ as lasting $\mathrm{Z}$ periods and producing, over $\mathrm{Z}$ periods, a maintainable RI equal to the timescaled RI. This is possible because the time- $T_{k}$ NPV may be compounded up to time Z. Distributing uniformly over Z periods, the time-scaled maintainable RI for Z periods is obtained. In a nutshell: a nonzero NPV project displays its effects even after the project is over. These effects are equal to the (accumulated) NPV variation period by period (see the example described in Section 5).

Requirements (A) and (B) are then both fulfilled. This implies that the time-scaled (average or maintainable) RI may be employed for both capital budgeting and incentive compensation. 


\section{Some Numerical Examples}

Consider the four projects illustrated in Table 2a-b, which focuses on the accept/reject decision. Residual income and average accounting rates are computed for straight line depreciation, Hotelling depreciation, maintainable-RI depreciation and a depreciation that is arbitrarily chosen with no particular economic meaning. The maximum length is $\mathrm{Z}=4$ periods and the NRP is a constant $5 \%$. First of all, note that projects 1, 2, 3 are profitable (positive NPV) and project 4 is not worth undertaking (negative NPV). The ARR rule correctly signals value creation for the three profitable projects (regardless of the asset base). The ARR margins measure the residual income per unit of total capital invested. For example, let us focus on straight-line depreciation. Project 1's ARR margin is $7.88 \%=15 \%-7.12 \%$, that is, 0.0788 euros of RI for any euro of capital invested. The total capital invested in the project is 2,000 $(=1,000+666.67+333.33)$, so that $\mathrm{NPV}_{3}=7.88 \% \cdot 2,000=157.6$. In the other depreciation patterns, the total capital invested changes, but rates change as well. For example, in the arbitrary depreciation pattern, project 1 is described as a total investment of 1,600 euros, which is smaller than the 2,000 euros previously found. However, the ARR margin is greater: $9.85 \%=18.75 \%-8.9 \%$. Applying this ARR margin to the grand total capital, one finds back $\mathrm{NPV}_{3}=9.85 \% \cdot 1,600=157.6$. Thus: project 1 may be viewed either as an investment of 2,000 euros generating excess profit at a rate of $7.88 \%$ or an investment of 1,600 euro generating excess profit at a rate of $9.85 \%$. As for project 1 's Hotelling depreciation, it is worth noting that IRR, simple arithmetic mean of ARRs and weighted average of ARRs coincide (see Corollary 3.1). Consider now project 3: in the maintainable-RI depreciation the total capital invested is $405-550.1=-145.1<0$ (the asset is described as an overall financing) so the ARR rule holds with the sign reversed: we have $4.13 \%<5.02 \%$ (the actual cost of financing is smaller than the maximum acceptable cost of financing), which correctly signals value creation. In the arbitrary depreciation schedule, we deliberately include a zero book value for project 2 at time 1 . This implies that neither the second-period ARR nor the second-period COC are defined; nonetheless, the average ARR and average COC are welldefined. The IRR rule fails in several ways: project 3 presents two IRRs (4\% and 36.98\%). Project 4 has no IRR and so nothing can be said as well. (Note also that the IRR fails to recognize that project 1 is more profitable than project 2 : one finds $\mathrm{NPV}^{1}=136.2>\mathrm{NPV}^{2}=113.9$ but $\mathrm{IRR}^{1}=10 \%<\mathrm{IRR}^{2}=14 \%$ ). However, in order to verify the economic viability of a project, the IRR margin may be soundly used, except for project 4 (IRR does not exist), provided that each IRR is contrasted to its own corresponding average COC. For example, considering project 3, both IRR (correct) margins are negative: $4 \%-4.9 \%<0$ and $36.98 \%-44.9 \%<0$; given that the project is viewed as a financing $(S<0)$, the IRR margins correctly signal value creation.

The average residual income and the time-scaled residual income are computed for every project as well. Note that the time-scaled RI correctly signals economic profitability and provides the same ranking

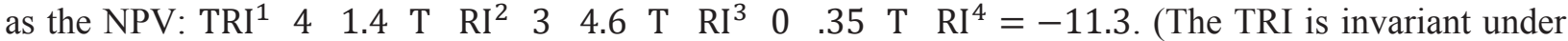
changes in book values, so no reframing of depreciation pattern is needed). Every project may be seen as a 4-period project generating a constant residual income equal to $\mathrm{TRI}^{k},=1,2,3,4$. To consider each project as a 4-period project is indeed a possible interpretation (see Table 3). The accumulated NPV at time 4 is no less significant than the accumulated NPV at any other time. For example, consider project 1. Its accumulated $\mathrm{NPV}$ is $\mathrm{NPV}_{3}=136.2 \cdot\left(1.05^{3}=157.6\right.$ at time 3 and $\mathrm{NPV}_{4}=157.6 \cdot(1.05=165.5$ at time 4. That is: at time 3 the investor will hold 157.6 euros more than he would have owned if he invested his capital at the NRP (5\%), and at time 4 he will own 165.5 euros more than he would have owned. Therefore, in the fourth period, the investor will gain $5 \%$ on 157.6 , which is equal to 7.88 . The latter is the residual income of the fourth period and is independent of the asset base, as long as the asset is completely depreciated at time 3 . In general, any $T$-period project keeps on producing RIs after the project is over (if NPV 0 ). Cash flows and incomes will be zero from $T+1$ on, but the capital charge will not, because the terminal unrecovered capital is not zero. In particular, the RIs generated after the last period will be equal to the increase of the accumulated NPV; that is, $\mathrm{RI}_{t}=-r_{t} b_{t-1}^{*}=r_{t} \cdot \mathrm{NPV}_{t-1}=$ $\mathrm{NPV}_{t} \mathrm{~N} \quad \mathrm{PV}_{t-1}$ for $t>T$, regardless of the depreciation pattern. 


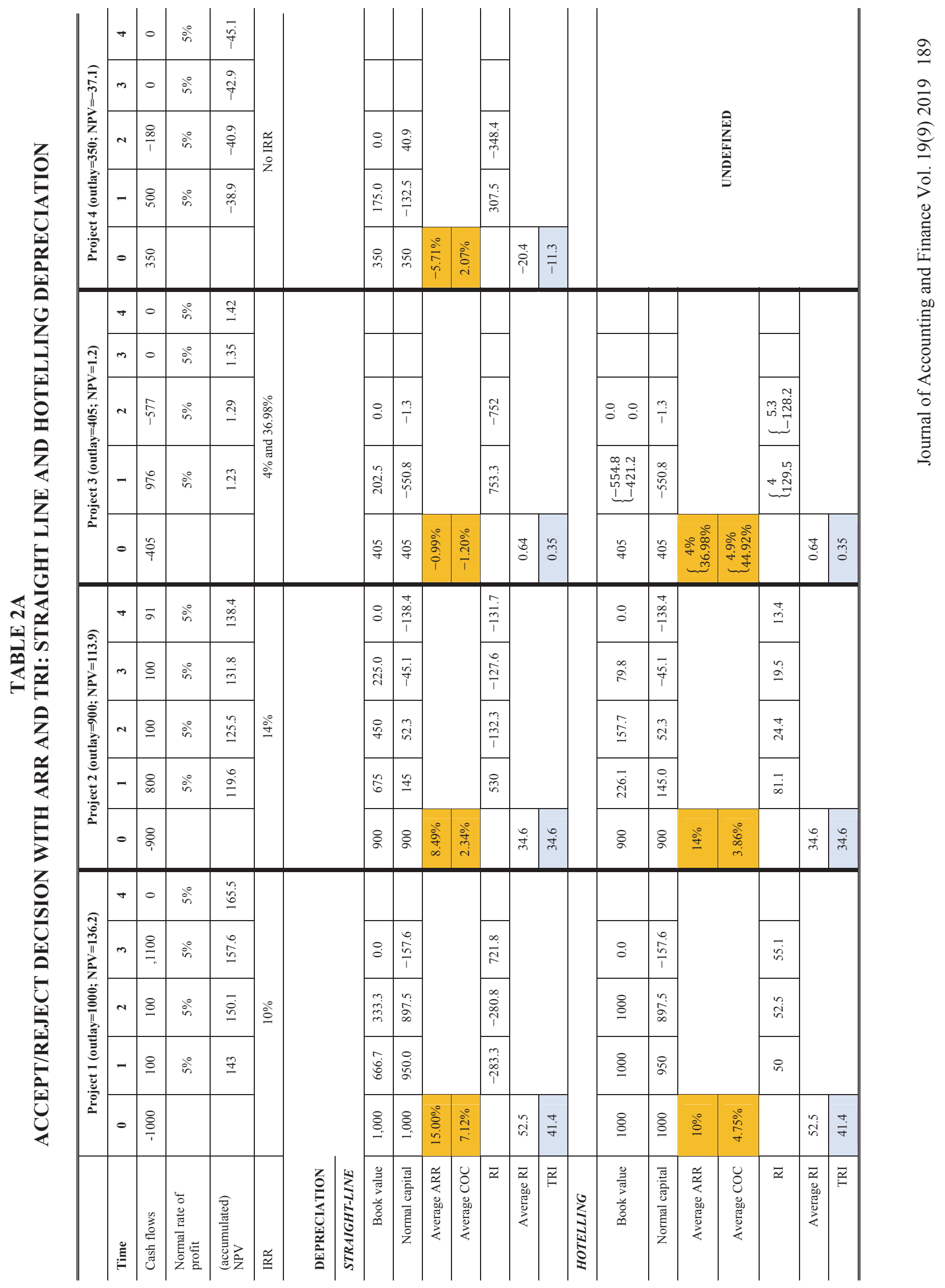




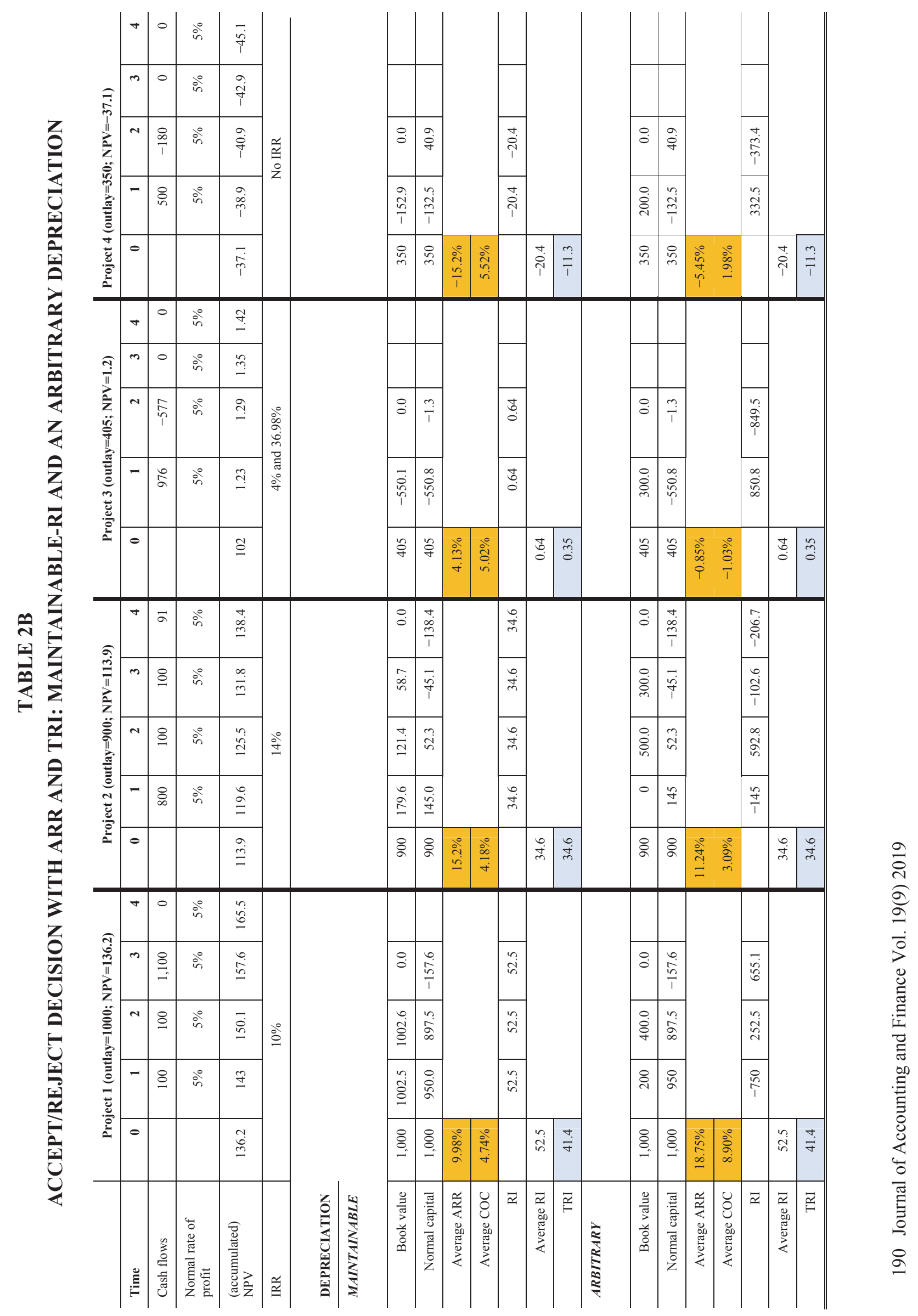


TABLE 3

PROJECT 1 AS A THREE-PERIOD OR FOUR-PERIOD PROJECT

\begin{tabular}{|c|c|c|c|c|c|c|c|c|c|}
\hline & \multicolumn{4}{|c|}{ Three periods } & \multicolumn{5}{|c|}{ Four periods } \\
\hline Time & 0 & 1 & 2 & 3 & 0 & 1 & 2 & 3 & 4 \\
\hline Cash flows & $-1,000$ & 100 & 100 & 1100 & $-1,000$ & 100 & 100 & 1,100 & 0 \\
\hline normal rate of profit & & $5 \%$ & $5 \%$ & $5 \%$ & & $5 \%$ & $5 \%$ & $5 \%$ & $5 \%$ \\
\hline $\begin{array}{l}\text { accumulated } \\
\text { NPV }\end{array}$ & 136.2 & 143 & 150.1 & 157.6 & 136.2 & 143 & 150.1 & 157.6 & 165.5 \\
\hline NPV increase & & 6.8 & 7.1 & 7.5 & & 6.8 & 7.1 & 7.5 & 7.88 \\
\hline \multicolumn{10}{|l|}{ Book value } \\
\hline $\begin{array}{r}\text { First depreciation } \\
\text { pattern }\end{array}$ & 1,000 & 666.7 & 333.3 & 0 & 1,000 & 666.7 & 333.3 & 0 & 0 \\
\hline $\begin{array}{r}\text { Second depreciation } \\
\text { pattern }\end{array}$ & 1,000 & 1,000 & 1,000 & 0 & 1,000 & 1,000 & 1,000 & 0 & 0 \\
\hline $\begin{array}{r}\text { Third depreciation } \\
\text { pattern }\end{array}$ & 1,000 & $1,002.54$ & $1,002.58$ & 0 & 1,000 & $1,002.54$ & $1,002.58$ & 0 & 0 \\
\hline $\begin{array}{r}\text { General depreciation } \\
\text { pattern }\end{array}$ & 1,000 & $b_{1}$ & $b_{2}$ & 0 & 1,000 & $b_{1}$ & $b_{2}$ & 0 & 0 \\
\hline \multicolumn{10}{|l|}{ Residual income } \\
\hline $\begin{array}{r}\text { First depreciation } \\
\text { pattern }\end{array}$ & & -283.3 & -280.8 & 721.8 & & -283.3 & -280.8 & 721.8 & 7.88 \\
\hline $\begin{array}{r}\text { Second depreciation } \\
\text { pattern }\end{array}$ & & 50.0 & 52.5 & 55.1 & & 50.0 & 52.5 & 55.1 & 7.88 \\
\hline $\begin{array}{r}\text { Third depreciation } \\
\text { pattern }\end{array}$ & & 52.5 & 52.5 & 52.5 & & 52.5 & 52.5 & 52.5 & 7.88 \\
\hline $\begin{array}{r}\text { General depreciation } \\
\text { pattern }\end{array}$ & & $\mathrm{RI}_{1}$ & $\mathrm{RI}_{2}$ & $\mathrm{RI}_{3}$ & & $\mathrm{RI}_{1}$ & $\mathrm{RI}_{2}$ & $\mathrm{RI}_{3}$ & 7.88 \\
\hline
\end{tabular}

Table 4 focuses on project 2 and shows the equivalence class $B$, ., which is Hotelling class. In other words, the project is described as an investment of a total 1,363.6 euros. The average ARR associated with this class is $\bar{a}(1363.6)=14 \%$ and is just the IRR. The Hotelling schedule is only an element of this class (Pattern 1).

Table 5 deals with the project studied by Vatter (1966, Tables 1-3) and Peasnell (1982a, Table 1). The equivalence class $B_{3,776}$. (Hotelling class) is described containing, among others, both Hotelling depreciation and Vatter's depreciation (see Vatter's, 1966, Table 2). 
TABLE 4

PROJECT 2 - THE EQUIVALENCE CLASS B ${ }_{1,363.6}$ (HOTELLING CLASS)

\begin{tabular}{|c|c|c|c|c|c|c|}
\hline $\begin{array}{l}\text { Time } \\
\text { Cash Flows }\end{array}$ & $\begin{array}{l}0 \\
-900\end{array}$ & $\begin{array}{l}1 \\
800\end{array}$ & $\begin{array}{l}2 \\
100\end{array}$ & $\begin{array}{l}3 \\
100\end{array}$ & $\begin{array}{l}4 \\
91\end{array}$ & $\begin{array}{l}\text { Average } \\
\text { ARR }\end{array}$ \\
\hline \multicolumn{7}{|l|}{$\begin{array}{l}\text { Book value } \\
\text { depreciation }\end{array}$} \\
\hline $\begin{array}{l}\text { Pattern } 1 \\
\text { (Hotelling) }\end{array}$ & 900 & 226.1 & 157.7 & 79.8 & 0 & \multirow{3}{*}{$14 \%$} \\
\hline ARR & & $14 \%$ & $14 \%$ & $14 \%$ & $14 \%$ & \\
\hline Pattern 2 & 900 & 200 & 100 & 163.6 & 0 & \\
\hline ARR & & $11.11 \%$ & $0 \%$ & $163.6 \%$ & $-44.38 \%$ & $14 \%$ \\
\hline Pattern 3 & 900 & 300 & 123.6 & 40 & 0 & \multirow{3}{*}{$14 \%$} \\
\hline ARR & & $22.22 \%$ & $-25.47 \%$ & $13.27 \%$ & $127.5 \%$ & \\
\hline Pattern 4 & 900 & 0 & 93.3 & 370.3 & 0 & \\
\hline ARR & & $-11.11 \%$ & undefined & $404.07 \%$ & $-75.43 \%$ & \multirow[t]{2}{*}{$14 \%$} \\
\hline Pattern 5 & 900 & 190 & 157 & 116.6 & 0 & \\
\hline ARR & & $10 \%$ & $35.26 \%$ & $37.96 \%$ & $-21.96 \%$ & $14 \%$ \\
\hline General pattern & 900 & $b_{1}$ & $b_{2}$ & $463.6-b_{1}-b_{2}$ & 0 & \\
\hline ARR & & $a_{1}$ & $a_{2}$ & $a_{3}$ & $a_{4}$ & $14 \%$ \\
\hline
\end{tabular}




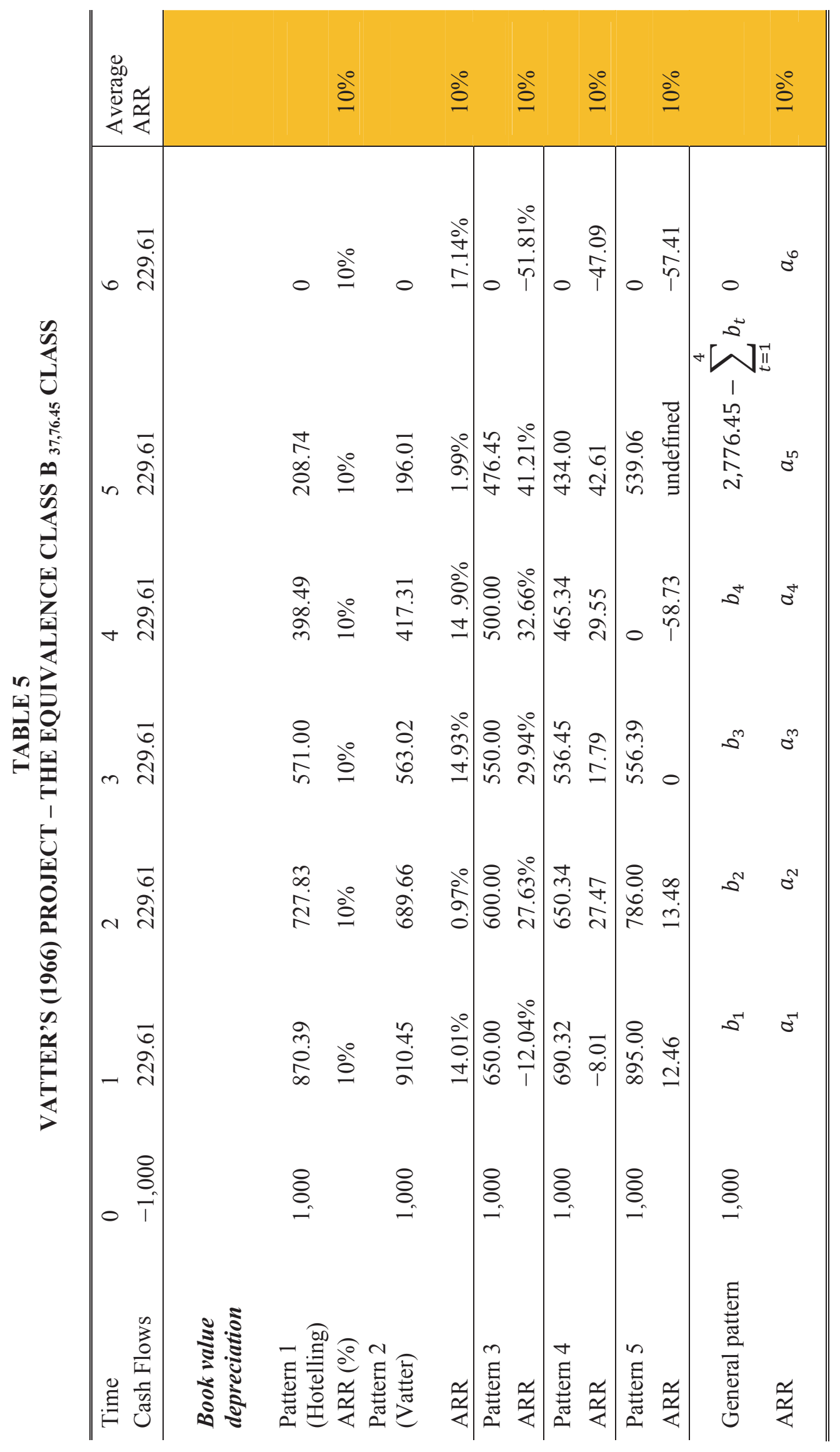

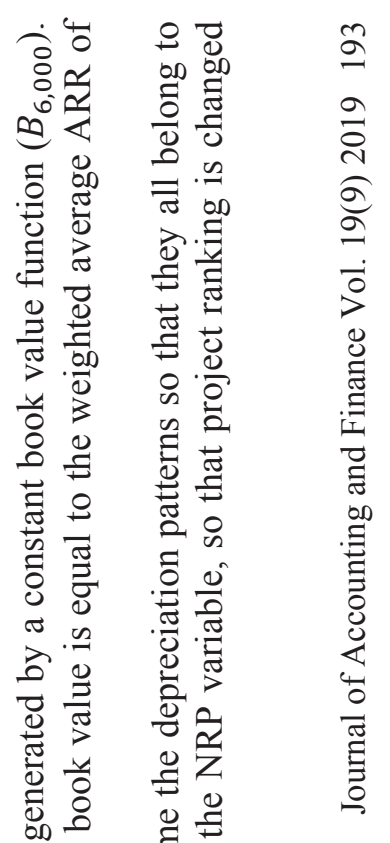

泀 焉

ङ 00 告

.

岂:

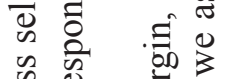

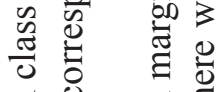

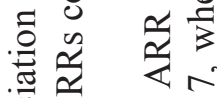

造

完范

気

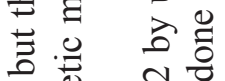

$\overline{\overline{0}} \quad \frac{0}{0} \cdot \frac{1}{2}$

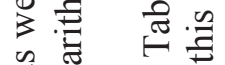

ส 0 पे

过 苍芯

을 的 $\frac{0}{0}=$

क छ 흠유

离言

专 五

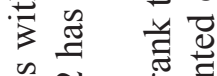

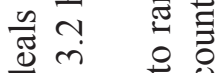

ర)

훙

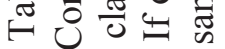

这唗 


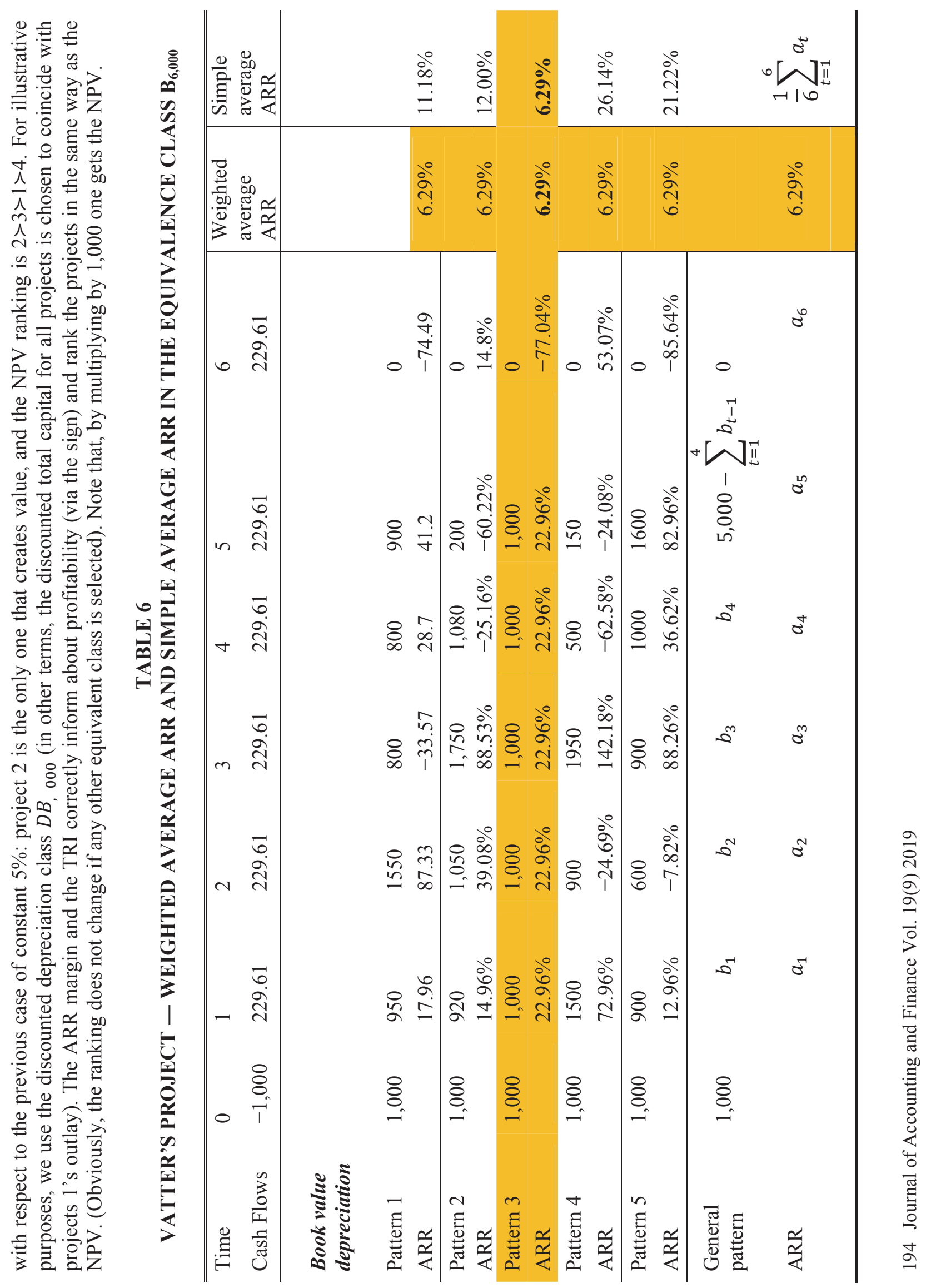




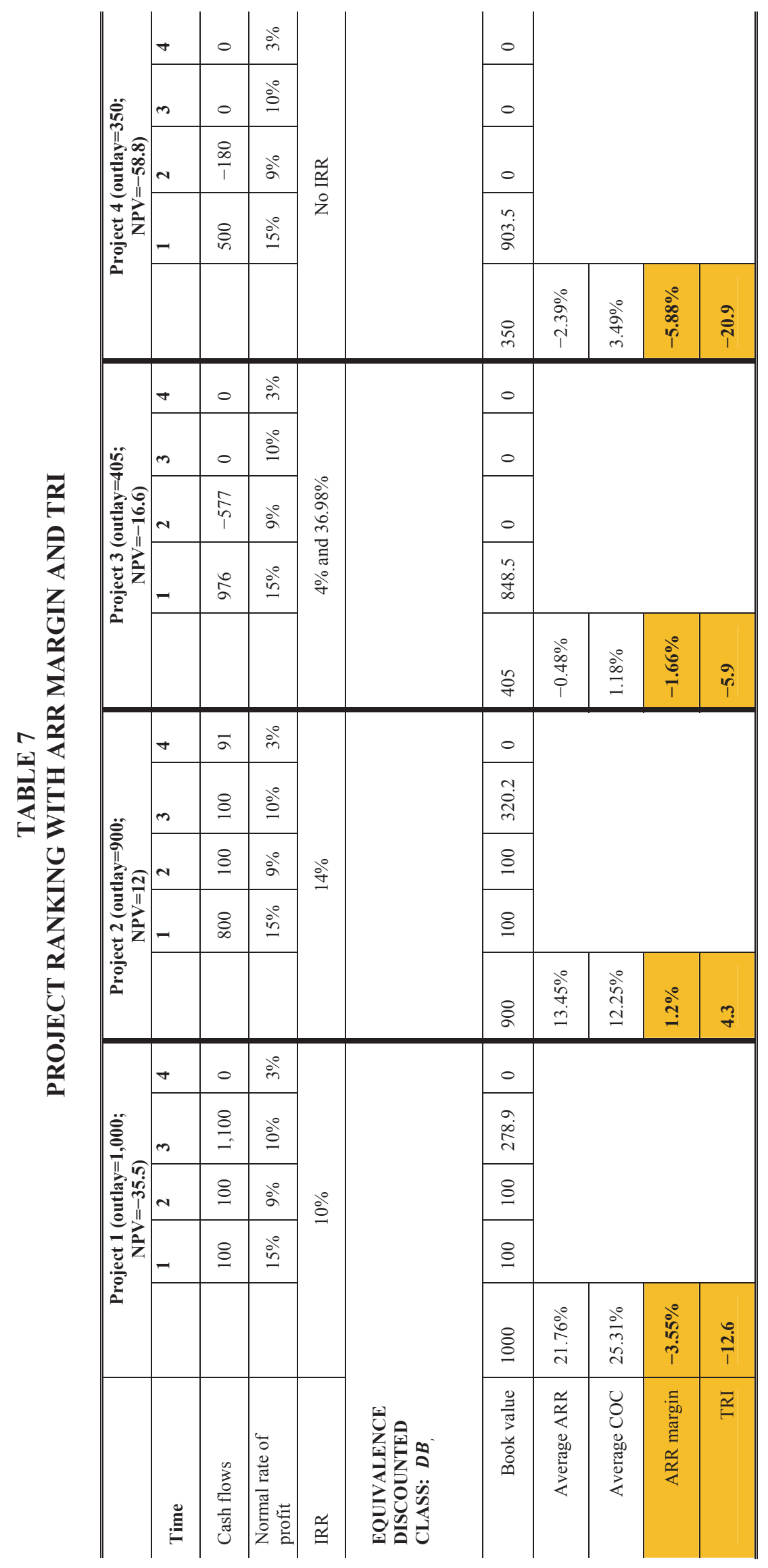

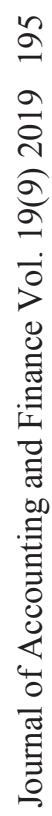




\section{Valuation and Asset Pricing}

The relations among ARR, RI, and NPV analyzed in the previous sections are relevant for valuation, and provide interesting links to asset pricing. Given that NPV=V-C_0 (see eq. (2)), one may write the project value as a function of the average RI:

$V=b_{0}+\alpha(T \cdot \overline{\mathrm{RI}}$.

This implies

$V=V(\bar{x})=\left[b_{0}-\alpha(T)(\bar{\varrho} \bar{b})\right]+\alpha(T) \cdot \bar{x}$

where $\bar{x}:=\frac{\sum_{t=1}^{T} x_{t}}{T}$ is the simple arithmetic mean of future incomes and $\bar{\varrho} \bar{b}=\frac{\sum_{t=1}^{T} r_{t} b_{t-1}^{*}}{T}$ is the simple arithmetic mean of future capital charges. The fact that an asset's value linearly depends on a simple average income is a powerful result of income aggregation. In terms of real-life applications, eqs. (17) and (18) give the investor an accounting-based valuation tool. There is no need of forecasting cash flows directly and, unlike the standard RI models, there is no need of forecasting each and every residual income. One just has to forecast the simple average RI or, equivalently, one has to forecast, on one hand, the simple average income and, on the other hand, the simple average capital charge. There are many situations where historical accounting data may be useful to this end.

Along with the simplification in the forecasting process, the use of an average of data rather than $T$ single data (as in the standard RI models) tends to offset forecasting errors. And the error is actually nil if it consists of an incorrect imputation of RI to periods: any permutation of the correct sequence $\left(\mathrm{RI}_{1}, \mathrm{RI}_{2}, \ldots, \mathrm{RI}_{T}\right)$ is value-neutral, given that value depends on the simple arithmetic mean of such a sequence. Therefore, to anticipate or postpone RIs in the forecasting process has no effect on value.

This just seems to be a findng that accounting was expected to provide and gives a solid quantitative footing to Graham, Dodd, and Cottle's (1962) auspicious statement:

The most important single factor determining a stock's value is now held to be the indicated average future earning power, i.e., the estimated average earnings for a future span of years. Intrinsic value would then be found by first forecasting this earning power and then multiplying that prediction by an appropriate "capitalization factor" (Graham, Dodd, and Cottle, 1962, p. 28, as quoted in Penman, 1992, p. 471).

The indicated average earning power is just $\bar{x}$ (or $\overline{\mathrm{R}} \overline{\mathrm{I}}$, if one prefers) and the appropriate capitalization factor is $\alpha(T)$, the market price of the project's length.

The link of an asset's value with each period's income is given by

$V=\left[b_{0}-\alpha(T) \cdot-\bar{b}\right]+v(\vec{r}), \quad\left(x_{1}+x_{2} \cdots+x_{T}\right)$.

Under certainty, the discount factor $v(\vec{r}), k, 1 \leq k \leq T, \in \mathbb{N}$, represents the unit price of a zerocoupon bond with maturity $k\left(r_{k}\right.$ is then the forward rate for the interval $\left.[k-1, k]\right){ }^{21}$

Let $V^{k}=V^{k}\left(x_{1}, x_{2}, \ldots, x_{k}\right)$ be the value of any $k$-period project and consider the set of all assets traded in the market. Denote with $\vec{V}=\left(V^{1}, V^{2}, \ldots, V^{T}\right), \in \mathbb{N}$, the vector of the assets' values.

The Jacobian matrix of $\vec{V}$ is 


$$
J=\left[\begin{array}{cccccc}
\frac{\partial V^{1}}{\partial x_{1}} & 0 & 0 & 0 & \ldots & 0 \\
\frac{\partial V^{2}}{\partial x_{1}} & \frac{\partial V^{2}}{\partial x_{2}} & 0 & 0 & \ldots & 0 \\
\frac{\partial V^{3}}{\partial x_{1}} & \frac{\partial V^{3}}{\partial x_{2}} & \frac{\partial V^{3}}{\partial x_{3}} & 0 & \ldots & 0 \\
\vdots & \vdots & \vdots & \ddots & \vdots & \vdots \\
\frac{\partial V^{T}}{\partial x_{1}} & \frac{\partial V^{T}}{\partial x_{2}} & \frac{\partial V^{T}}{\partial x_{3}} & \frac{\partial V^{T}}{\partial x_{4}} & \ldots & \frac{\partial V^{T}}{\partial x_{T}}
\end{array}\right]
$$

The derivative $\frac{\partial V^{k}}{\partial x_{s}}, s, k=1,2, \ldots, T$, is the element $(k, s)$ of the Jacobian matrix and measures the value increase of a $k$ - period asset due to a unit increase in income at time $s$. It is worthwhile noting that $\frac{\partial V^{k}}{\partial x_{s}} 0$ for $s>k$ and, given the additive coherence, changing subscripts does not change the derivative: $\frac{\partial V^{k}}{\partial x_{1}}=\frac{\partial V^{k}}{\partial x_{2}} \cdots \quad \frac{\partial V^{k}}{\partial x_{k}}$ for all $k$. This means that the effect of income increase on value is the same, no matter when the income increase occurs. In particular, from (19) one gets to

$\frac{\partial V^{k}}{\partial x_{s}}=v(\vec{r}), \quad=\frac{1}{\left.\left(1+r_{1}\right)\left(1+r_{2}\right) \cdots 1+r_{k}\right)}$

for all $k=1,2, \ldots, T$, for all $1 \quad s \leq k$, and for all $x_{s} \in$. Then, we have proved the following

Proposition 6.1. In a capital market, the yield term structure is described by the Jacobian matrix of the assets'values with respect to incomes.

Thus, the market univocally determines the impact of accounting income on all assets' values. We stress that the derivative $\frac{\partial V^{k}}{\partial x_{s}}$ is independent of the asset chosen and of the period where the income increase is originated: it only depends on the asset's length. Thus, the value of any $T$-period project generating the cash-flow vector $\left(F_{1}, 2, \ldots F_{T}, \quad T \in \mathbb{N}\right.$ is

$V^{T}=F_{1} \frac{\partial V^{1}}{\partial x_{k_{1}}}+F_{2} \frac{\partial V^{2}}{\partial x_{k_{2}}} \cdots+F_{T} \frac{\partial V^{T}}{\partial x_{k_{T}}}$

where $k_{s}$ is an arbitrary natural number between 1 and $s, s=1,2, \ldots$,. Therefore, the sum of a project's discounted cash flows is a linear combination of the value derivatives, with cash flows as coefficients. From Proposition 6.1 and the structure of the Jacobian matrix, one derives the following

Corollary 6.1. Consider a T-period asset. A cash flow increase for an asset at time $T$ is financially equivalent to an equal income increase for that asset occurred at any time.

Proof: If the asset's cash flows are increased at time T, the impact on value is $v(\vec{r}), T$. If the asset's incomes are equally increased at any time $\mathrm{k}_{\mathrm{T}} \mathrm{T}$, the impact on value is $\frac{\partial \mathrm{V}^{\mathrm{T}}}{\partial \mathrm{x}_{\mathrm{k}_{\mathrm{T}}}}$. The thesis follows from $(20)$

Note that the income increase may be arbitrarily distributed over the interval $[0, T]$. The relevant assumption is that the total increase in income is equal to the cash flow increase occurred at time $t$. Note 
also that the proposition refers to income increase in the asset itself, but the result would be the same with reference to an income increase to any $T$-period asset (derivatives are equal for all assets traded in the market, as long as their length is the same).

Corollary 6.2. Consider a T-period asset. A cash flow increase in the asset at time $t<T$ is financially equivalent to an equal income increase, occurred at any time, in any t-period asset.

Proof: If the asset's cash flows are increased at time $t$, the impact on value is $v(\vec{r}), t$. If an income of any $t$-period asset is equally increased at any time $k_{t} \leq t$, the impact on value is $\frac{\partial V^{t}}{\partial x_{k_{t}}}$. The thesis follows from (20)

Actually, these two corollaries just say that the derivatives with respect to cash flow and with respect to income coincide. This is easily seen from (21): taking the derivative with respect to $F_{t}$ one gets

$$
\frac{\partial V^{T}}{\partial F_{t}}=\frac{\partial V^{t}}{\partial x_{k_{t}}}
$$

But, again, note that the left-hand side refers to time $t$, whereas the right-hand side refers to any time $k_{t}$ in the span $[0, t]$.

Remark 6.1. The NRP may now be written as

$$
r_{s}=\frac{\frac{\partial V^{s-1}}{\partial x_{k_{s-1}}}}{\frac{\partial V^{s}}{\partial x_{k_{s}}}} 1
$$

where $\frac{\partial V^{0}}{\partial x_{k_{0}}}:=1$, so that, using (19), one may also write a $T$-period project's value as

$$
V^{T}=b_{0}+\frac{\partial V^{T}}{\partial x_{k_{T}}}\left(\sum_{s=1}^{T} x_{s}-\sum_{s=1}^{T} \frac{\frac{\partial V^{s-1}}{\partial x_{k_{s-1}}}}{\frac{\partial V^{s}}{\partial x_{k_{s}}}} b_{s-1}^{*}\right)
$$

where the $k_{s}$ 's are arbitrary indexes between 1 and $s$.

\section{Some Educational Implications}

From an educational point of view, the use of accounting in order to interpret such notions as net present value, normal rate or profit, internal rate of return, cost of capital, asset pricing may facilitate financial reasoning among accountants.

First, a project NPV is nothing but a residual income, being obtained as the difference between total accounting income and a capital charge which measure the total foregone return, based on normal capital and normal rate of return: $\mathrm{NPV}_{T}=\sum_{t=1}^{n} x_{t}-\sum_{t=1}^{n} r_{t} b_{t-1}^{*}$. In terms of accounting rates, a project NPV is broken down into the project's size, $S$, and the financial efficiency, measured as a residual rate of return, $\bar{a}-\bar{\varrho}: \mathrm{NPV}_{T}=S(\bar{a}-\bar{\varrho})$.

Further, the equality

$$
V^{T}=\alpha(T) \cdot{ }^{-}+\left[b_{0}-\alpha(T) \cdot-\bar{b}\right]
$$


enables one to consider the market value of a project or a firm as a sum of two accounting components; the first one is income-based: it is an average income scaled for taking account of the project's length; the second one is book value-based: it is a net book value, that is, net of the average capital charge (adjusted for time as well). Comprehension of financial measures may be improved by inviting managers and accountants to interpret the unit price of zero-coupon bonds (or the unit price of equivalent-risk assets) as the market-determined effect of income on value. Asset pricing is then viewed as an accounting process by means of which the market determines how income affects value.

The internal rate $i$ is always presented as a root of a polynomial expression where book values do not appear, so that the IRR has no direct connection with the project's NPV: no wonder if accountants do not see the IRR as an average accounting rate corresponding to a depreciation class and if the NPV is considered extraneous to an accounting line of a reasoning. To teach the IRR notion by resorting to the usual discounted-cash-flow equation is not a good educational strategy, for a complex counterfactual reasoning is implied in the equation: "if the normal rate of profit were constant and if it were equal to the solution of the equation, then the project would be value-neutral". This clouds the IRR's accounting nature and conceals the fact that the IRR is a mean. It is more natural to think of an average ARR that leaves the actual NPV unvaried (which is what one expects from an average). The IRR may then be defined as an average ARR which leaves unvaried the NPV of the project and which corresponds to a particular depreciation class (conventionally called "Hotelling" class) among the infinite ones that an accountant may in principle select. Hence, $\mathrm{NPV}_{T}=H(i-\bar{\varrho}(H))$.

The normal rate of profit has a straightforward accounting interpretation: it is the COC corresponding to the normal depreciation class; that is, if the normal class is used to describe the project, then $r=\bar{\varrho}\left(S^{*}\right)$. The capital charge is easily grasped if one invites accountants to just construct pro forma income statements and balance sheets for two alternative economic situations: (i) funds are invested in the project (ii) funds are invested at the normal rate of profit. After the alternative financial statements have been constructed, one only has to invite accountants to compute the difference between the profits in one case and the profits in the opposite case. The results are, on one side, the actual profits $x_{t}$ and, on the other side, the normal profits $i_{t} b_{t-1}^{*}$. Hence, the lost-capital RI is a difference of the two profits (see pro forma balance sheets in Magni, 2003, where residual income is called "systemic value added"). In such a way, the microscope of the scholar is taken away from the IRR, which loses noteworthiness to the benefit of the more general ARR. As it should: the heart of the matter is the average ARR and the ARR margin: whatever depreciation class, the overall economic analysis does not change. And given that residual income "is arguably a more intuitively understandable concept than is NPV" (Peasnell, 1982a, p. 377), one just has to remind that the ARR margin $\bar{a}-\bar{\varrho}$ is the residual income per unit of total capital invested. The latter, multiplied by the average book value, is the (average) RI, which is received $T$ times. Hence, the time- $T$ NPV. (And the average ARR may now be viewed as the sum of the cost of capital and the time- $T$ NPV per unit of capital invested: $\bar{a}=\bar{\varrho} \mathrm{N} \mathrm{PV}_{T} /$ ).

The network of relations existing among NPV, IRR, average ARR, income, residual income, average residual income, is easily recognized:

1) $\mathrm{NPV}_{T}=\sum_{\mathrm{t}=1}^{\mathrm{n}} x_{t}-\sum_{t=1}^{n} r_{t} b_{t-1}^{*}$

2) $\mathrm{NPV}_{T}=S(\bar{a}-\bar{\varrho})$

3) $i=\bar{a}(H)$

4) $i=\bar{\jmath}(H)+\frac{\mathrm{NPV}_{T}}{H}$

5) $\mathrm{NPV}=v(\vec{r}), \quad H(r-\bar{\varrho}(H))$

6) $\mathrm{NPV}=v(\vec{r}), \quad \sum_{t=1}^{T} \mathrm{RI}_{t}(H)$

7) $\overline{\mathrm{RI}}=\left(i-\bar{\varrho}(H) \cdot \frac{H}{T}\right.$

8) $\mathrm{TRI}=\frac{\mathrm{NPV}_{Z}}{Z}$

9) $\bar{x}=\frac{\bar{\varrho}(H) H}{T}+\frac{\mathrm{NPV}_{T}}{T}$ 
with $H$ : = sum of Hotelling book values. The interpretations are straightforward:

1) the NPV is a grand total residual income, namely, the difference between total income and total normal income

2) the NPV is the product of the project's scale and the project's efficiency, as measured by accounting an average ARR

3) an IRR is an average ARR corresponding to a Hotelling class

4) an IRR is the sum of the cost of capital corresponding to a Hotelling class and the accumulated NPV per unit of total capital invested

5) the NPV is equal to the market value of total Hotelling book values multiplied by the IRR (correct) margin

6) the NPV is the market value of the sum of Hotelling residual incomes

7) the average RI is the IRR (correct) margin, multiplied by average Hotelling book value

8) the time-scaled RI is the average time- $Z$ NPV per period (if $Z=T$, then TRI $=\overline{\mathrm{RI}}$ )

9) the average income is the sum of the average capital charge per period and the average accumulated NPV per period.

In all this, the use of means is essential in simplifying explanations. Means are educationally appealing, intuitive and widespread in real life. Unlike the naïve applications of the mean notion often encountered in practice, we have shown that a rigorous treatment is possible in order to draw significant means which can effectively induce correct economic reasoning by accountants.

\section{CONCLUDING REMARKS}

This paper presents a theory of capital budgeting by providing the mathematical relations that connect accounting measures and economic measures. The literature has so far focused on the internal rate of return (IRR) as a privileged index informing about economic profitability, and has judged the (average) accounting rate of return (ARR) in terms of its errors with respect to the IRR. In other words, the accounting and financial literature has so far assumed that IRR is the economic rate of return of a project, and have opposed accounting rates of return and IRR. Also, it has opposed residual income to NPV as periodically incompatible indexes.

This paper reverses the perspective; it shows that the dichotomy IRR/ARR and economic/accounting is artificial: income, ARR, residual income, NPV, IRR are all, at the same time, economic and accounting measures bearing simple, intuitive, elegant relations one another.

In particular,

- the IRR is equal to the Chisini mean of the accounting rates associated with the discountedcash-flow function where ARRs are the independent variables. The choice of such a function for defining an internal rate of return is ill-fated, because neither existence nor uniqueness is guaranteed, and the accounting nature of the IRR is concealed

- the Chisini mean of the accounting rates associated with an appropriate RI function is the long neglected weighted average of ARRs

- for any project, the set of all possible depreciation patterns is partitioned into equivalence classes: an equivalence class collects all depreciation schedules with the same grand total capital invested. It is always possible to choose the same depreciation class for decision and valuation purposes. This entails that maximization of the ARR margin (possibly discounted for projects of unequal life) is equivalent to NPV maximization

- the average ARR is a correct economic yield; in particular, (i) it is a genuinely internal rate (unaffected by normal rates), (ii) it is equal to the average COC if and only if the NPV is zero, (iv) an investment's NPV is positive if and only if the average ARR is greater than the average COC, regardless of book values, (iii) given a project, the ARR function exists and is unique 
- the IRR is an average ARR associated with the depreciation class of those schedules which are equivalent to Hotelling depreciation. There are infinite depreciation schedules that share the same IRR

- the simple average of ARRs may be soundly contrasted with the simple average of COCs, as long as a constant book value function is selected. In a fixed-income asset, the weighted average ARR corresponding to the Hotelling class coincides with the simple average ARR as well as with the IRR

- the (constant) normal rate of profit is the cost of capital corresponding to the class of normal (unrecovered) book values

- the NPV is a positive linear transformation of the simple arithmetic mean of residual incomes, so NPV maximization is equivalent to maximization of average RI (possibly timescaled if projects have unequal life)

- an aggregation result holds: each and every residual income is not needed for valuation purposes; what counts is the average RI. This tends to offset forecasting errors in valuation

- the maintainable RI is the constant RI which is obtained by imposing that the abnormal capital per period be constant through time. This RI is equal to the average RI, which is instead obtained from any book value depreciation

- time-scaled RI and maintainable RI enjoy periodic consistency in the sense of Egginton (1995), regardless of book values. Thus, they may be used for incentive compensation as well

- the value of an asset is a linear affine function of income and residual incomes. The impact of income on value is equal to the impact of cash flow on value. In particular, the impact of income on value is market-determined and equals the market price of one euro available in the future. If cash flows are certain, the derivatives of a $t$-period asset's value with respect to income are equal to the unit price of zero-coupon bonds (if cash flows are uncertain, the derivatives are equal to the unit price of equivalent-risk assets). The value of any asset is a linear combination of such derivatives, with cash flows as coefficients.

- a new accounting-based definition of investment and financing is implicitly derived: an asset is an investment if the sum of book values is positive, whereas it is a financing if that sum is negative; in principle, given a cash-flow stream, any asset may either be seen as an investment or a financing.

The harmonization of these important (economic and accounting) notions has been possible thanks to three fundamental links:

1. the fundamental law of motion according to which book value depreciation equals difference between income and cash flow

2. the notion of lost-capital residual income, which makes use of an appropriate comprehensive capital charge such that the unrecovered capital is taken into account as well as the foregone return rate (normal rate of profit).

3. the definition of Chisini mean, which turns out to be a powerful tool for gathering economic information from a sample of accounting data.

The lost-capital residual income (Magni, 2003, 2009a, 2010a) enables one to show that the average $\mathrm{RI}$ is a significant economic measure, independent of accounting policies, and to realize that an asset is completely described economically by an accounting triplet: average ARR, average COC, total book value. ${ }^{22}$ And it allows to state that the IRR obsession is just a cognitive illusion, because the IRR is, whenever it exists, (not a constant period rate of return but) one average ARR among other possible ones. Specifically, it is an average ARR associated with Hotelling depreciation class, which includes infinite equivalent depreciation schedules with non-constant period rates of return. And the Hotelling depreciation class is, in turn, only one among infinite depreciation classes that one may consider for a project. It is a wonder that, despite its serious flaws for valuation and decision purposes (see Magni 2013 for a compendium), the IRR, instead of being considered the black sheep of the accounting family, is still considered "the" economic yield. 
In all this, the use of means is crucial: unlike the naïve applications of means often encountered in practice, this work derives means in a rigorous way, by application of Chisini's (1929) notion of mean. Such means provide profound insights in the economic analysis of a project and offer simple and effective valuation tools and decision rules. The kinds of means obtained are familiar and widespread in real life, owing to their intuitiveness and appeal: simple arithmetic means and weighted arithmetic means. Accounting may really become an effective educational tool for spreading rigorous economic reasoning. A golden age for accountants?

\section{ENDNOTES}

1. The symbol $v(t)$ in Kay (1976) denotes book value.

2. See Brief (1999) for an analysis of 26 properties of the constant ARR.

3. The analysis allows for a bounded-rationality approach as well, in which case normal rates of profit are subjectively-determined satisficing thresholds in the sense of Simon $(1955,1957)$ (See also Magni 2009b on this issue).

4. Inexistence of IRR is more frequent than usually believed. From an equity perspective, the IRR of the equity cash-flow stream does not exist whenever the project is not financed by equity (i.e., it is financed by debt borrowing and/or decrease of cash and/or sales of financial assets). Inexistence of IRR springs up even in simple cases. For example, suppose a firm's managers invest $\$ 100$ in plant and machinery in a 3-period project with prospective cash flows equal to $\$ 40, \$ 50, \$ 110$ at time 1,2 , and 3 , respectively. The purchase of fixed assets is financed with the firm's liquid assets (by withdrawing $\$ 100$ from bank accounts or by selling marketable securities). Suppose the interest rate on the firm's liquidity is $2 \%$. This implies that equityholders will forego the interest income on $\$ 100$ but, at the same time, will receive the project's operating cash flows. The equity investment is described by the cash flow sequence $(0,40,50,110-$ $\left.100(1.02)^{3}\right)=(0,40,50,3.88)$ and the IRR of this cash-flow stream does not exist. (Same result if, instead of liquid assets, the firm financed the project with debt at a $2 \%$ interest rate.)

5. Multiplicity is not rare as well (e.g., multiple IRRs occur in Rotating Savings and Credit Association. See Lima e Silva et al. 2018).

6. For example, the project with cash-flow vector 4,12, 9 has a unique IRR equal to $i=0.5$, but the NPV is negative for any other rate.

7. A flaw of the IRR is overlooked in the literature, and is a paradox: the IRR is defined as the rate of return that makes the NPV zero. Yet, despite this definition, there are zero-NPV projects which are not detected by the IRR. Consider the project 350, 500,-180). The IRR does not exist, and an IRR upholder would deem any information about the normal rate of profit irrelevant: given that NPV $(i)=-350+5001+$ $\left.i)^{-1}-1801+i\right)^{-2} 0$ for every $\in(-1,+\infty)$, the project is not worth undertaking. But suppose that the vector of the NRPs is $\vec{\imath}=(0,20 \%)$. This means that the project's NPV is zero: $-350+5001+$ $0^{-1}-180\left[\left(\begin{array}{lll}1 & 0\end{array}\right)\left(\begin{array}{ll}1 & 0.2\end{array}\right)\right]^{-1} 0$. Yet, the opposite conclusion is drawn from the IRR equation: the NPV may not be zero. And note that the project is not economically unprofitable: it is value-neutral. (Furthermore, if the vector of NRPs were $\vec{\imath}=(1 \%, 30 \%)$, the project's NPV would be 7.96 , which means value is created).

8. Hazen's (2003) interesting proposal solves problems a)-c), while leaving untouched problems d)-e). Also, the solution for a), technically impeccable, is devoid of economic meaning: "We are currently unaware of an economic interpretation of complex-valued rates of return or complex-valued investment streams, and without such an interpretation, it would be hard to justify any economic recommendation without resort to other performance measures such as present value" (Hazen, 2003, p. 44).

9. Stark (1989, p. 75, endnote 1) underlines the fact that Hotelling depreciation is mis-named, because Hotelling (1925) uses the cost of capital, not the IRR. We will use the expression "Hotelling depreciation" in the more common meaning of "IRR-implied depreciation".

10. In actual facts. they derived two decision rules (see Magni 2014, 2016).

11. See also the equivalent notion of Aggregate Return On Investment (Magni 2011).

12. This is intuitive: if $S<0$, the project is, on average, a financing. Therefore, interest rates reverse their roles: the average $\mathrm{COC}$ is a remuneration rate, and the average ARR is a rate of cost.

13. In the theorems above we have implicitly assumed, $Q>0$. If , $Q<0$ (the asset is a financing), the correct policy is reversed: "minimize the ARR margin". 
14. While we have implicitly assumed $H \neq 0$, the result holds for $H=0$ as well, because the latter equality entails $\sum_{t=1}^{T} h_{t-1} 0$, and any $a \in \mathbb{R}$ satisfies the equation $a \quad 0=0$. This means that, a fortiori, $i=\bar{a}(0)$.

15. Vatter (1966) just shows a numerical example where a depreciation schedule belongs to a Hotelling class (see Tables 1-3 therein).

16. Assets with the same initial outlay $F_{0}$ might be considered as investments with capital base equal to $S=-F_{0}$ if, for all projects, one sets $b_{t} 0$ for $t>0$.

17. However, zero total book value is a theoretical case devoid of practical interest. By contrast, inexistence of the IRR (and of Hotelling depreciation) is empirically evidenced and may not be amended.

18. In accept/reject decisions, the IRR margin has the same sign as the ARR margin if the project belongs to the class of Soper projects (see Appendix.)

19. Note that this is a Chisini mean as well, associated with the function $g\left(\mathrm{RI}_{1}, \mathrm{RI}_{2}, \ldots, \mathrm{RI}_{T}\right)=$ $v(\vec{l}), \quad \sum_{t=1}^{T} \mathrm{RI}_{t}$.

20. The NPV actually represents a terminal excess capital, because $\mathrm{NPV}_{T}=b_{T}-b_{T}^{*}$.

21. If uncertainty is assumed, the discount factor is the unit price of equivalent-risk assets.

22. A significant arithmetic mean may be derived from the standard notion of residual income as well, but it depends on the normal rate of profit (see Magni, 2010b).

\section{REFERENCES}

Adler, M. (1970). The true rate of return and the reinvestment rate. The Engineering Economist, 15, 185187.

Anctil, R. (1996). Capital budgeting using residual income maximization. Review of Accounting Studies, $1(1), 9-34$.

Anctil, R., Jordan J.S., \& Mukherji. (1998). The asymptotic optimality of residual income maximization, Review of Accounting Studies, 2(3), 207-229.

Anthony, R.N. (1975). Accounting for the Cost of Interest. Lexington, MA: D.C. Heath and Company.

Arnold, G., \& Davies, M. (Eds.) (2000). Value-based Management: Context and Application. Chichester, UK: John Wiley \& Sons.

Arrow, K.J., \& Levhari, D. (1969, September). Uniqueness of the internal rate of return with variable life of investment. The Economic Journal, 79, 560-566.

Aucamp, D.L., \& Eckardt, W.L. (1976, June). A sufficient condition for unique non-negative internal rate of return: Comment. Journal of Financial and Quantitative Analysis, 11, 329-332.

Bailey, M.J. (1959, October). Formal criteria for investment decisions. Journal of Political Economy, 67, 476-488.

Baldenius, T., \& Reichelstein, S., (2005). Incentives for efficient inventory management: The role of historical cost. Management Science, 51(7), 1032-1045.

Bernhard, R.H. (1977, March). Unrecovered investment, uniqueness of the internal rate, and the question of project acceptability. Journal of Financial and Quantitative Analysis, 12, 33-38.

Bernhard, R.H. (1979, June). A more general sufficient condition for a unique internal rate of return. Journal of Financial and Quantitative Analysis, 14, 337-341.

Bernhard, R.H. (1996). A simplification and an extension of the Bernhard-de Faro sufficient condition for a unique non-negative internal rate of return. Journal of Financial and Quantitative Analysis, (15), 201-209.

Bodenhorn, D. (1964, March). A cash-flow concept of profit. Journal of Finance, 19(1), 16-31.

Boulding, K.E. (1935, May). The theory of the single investment. Quarterly Journal of Economics, 49, 475-494.

Boulding, K.E. (1936a, May). Time and investment. Economica, 3, 196-220

Boulding, K.E. (1936b). Time and investment: A reply. Economica, 3 (November), 440-442.

Brief, R.P. (1996). Using accounting data in present value models. The Journal of Financial Statement Analysis, (Summer), 21-29.

Brief, R.P. (1999). The accounting rate of return as a framework for analysis. Retrieved from http://ssrn.com/abstract $=184228$ 
Brief, R.P., \& Lawson, R.A. (1992). The role of the accounting rate of return in financial statement analysis. The Accounting Review, 67(2), 411-426. Reprinted in R. Brief \& K.V. Peasnell (Eds.), A Link Between Accounting and Finance. New York: Garland, 1996.

Brief, R.P., \& Peasnell, K.V. (Eds.) (1996). Clean Surplus: A Link Between Accounting and Finance. New York and London: Garland Publishing.

Chisini, O. (1929). Sul concetto di media [On the concept of mean]. Periodico di matematiche, 4, 106116.

de Finetti, B. (2008). The concept of mean. In de Finetti, B., Philosophical Lectures on Probability, edited by Alberto Mura. Springer Science.

Dorfman, R. (1981, December). The meaning of internal rates of return. The Journal of Finance, 36(5), $1011-1021$.

Duhem, P. (1914). La théorie physique: son object et sa structure. Paris: Marcel Rivière.

Edey, H.C. (1957). Business valuation, goodwill and the super-profit method. Accountancy, January/February. Reprinted in W.T. Baxter \& S. Davidson (1962) (Eds.), Studies in Accounting Theory. London: Sweet \& Maxwell, pp. 201-217.

Edwards, E., \& Bell, P. (1961). The Theory and Measurement of Business Income. Berkeley University of California Press.

Edwards, J., Kay, J., \& Mayer, C. (1987). The Economic Analysis of Accounting Profitability. Oxford: Clarendon Press.

Egginton, D. (1995). Divisional performance measurement: residual income and the asset base. Management Accounting Research, 6, 201-222.

Feltham, G.A., \& Ohlson J.A. (1995). Valuation and clean surplus accounting for operating and financial activities. Contemporary Accounting Research, 11(2) (Spring), 689-731.

Fernández, P. (2002). Valuation Methods and Shareholder Value Creation. San Diego, CA: Elsevier Science.

Feenstra, D.W., \& Wang, H. (2000). Economic and accounting rates of return. Research Report, 00E42, University of Groningen, Research Institute SOM (Systems, Organisations and Management). Retrieved from http://som.eldoc.ub.rug.nl/FILES/reports/themeE/2000/00E42/00E42.pdf

Fetter, F.A. (1937). Reformulation of the concepts of capital and income in economics and accounting. The Accounting Review, 12(1), 3-12.

Fisher, F.M., \& McGowan, J.J. (1983, March). On the misuse of accounting rates of return to infer monopoly profits. American Economic Review, 73(1), 82-97.

Flemming, J.S., \& Wright, J.F. (1971, June). Uniqueness of the internal rate of return: A generalization. The Economic Journal, 81, 256-262.

Franks, J.R., \& Hodges, S.D. (1984). The meaning of accounting numbers in target setting and performance measurement: implications for managers and regulators. Presented at the Annual Meeting of the American Finance Association, San Francisco, 28-30 December 1983. Reprinted in R. Brief \& K.V. Peasnell (Eds.), A Link Between Accounting and Finance. New York: Garland, 1996.

Gallo, P., \& Peccati, L. (1993). The appraisal of industrial investments: a new method and a case study. International Journal of Production Economics, 30-31, 465-476.

Ghiselli Ricci, R., \& Magni, C.A. (2009). Axiomatization of residual income and generation of financial securities. Retrieved from http://papers.ssrn.com/abstract=1372371

Gjesdal, F. (2007). Discussion of "Conservatism, growth and return on investment. Review of Accounting Studies, 12(2-3), 371-376.

Gordon, L.A. (1974). Accounting rate of return vs. economic rate of return. Journal of Business Finance \& Accounting, 1(3), 343-356.

Gordon, L.A., \& Stark, A.W. (1989). Accounting and economic rates of return: A note on depreciation and other accruals. Journal of Business Finance \& Accounting, 16(3) (Summer), 425-432.

Graham, B., Dodd, D., \& Cottle, S. (1962). Security Analysis: Principles and Techniques, fourth edition. New York: McGraw-Hill. 
Graziani, R., \& Veronese, P. (2009, February). How to compute a mean? The Chisini approach and its applications. The American Statistician, 63(1), 33-36. doi:10.1198/tast.2009.0006.

Grinyer, J.R. (1985). Earned Economic Income - A theory of matching. Abacus, 21(2), 130-148.

Grinyer, J.R. (1987). A new approach to depreciation. Abacus, 23(2), 43-54.

Gronchi, S. (1986, March). On investment criteria based on the internal rate of return. Oxford Economic Papers, 1, 174-180.

Gronchi, S. (1987). Tasso di rendimento e valutazione dei progetti [Rate of return and project evaluation]. Milano: Franco Angeli.

Hajdasinski, M.M. (1986). On relevant and irrelevant rates of return. The Engineering Economist, 32(4) (Summer), 347-353.

Hajdasinski, M.M. (2004). Technical note-the internal rate of return (IRR) as a financial indicator. The Engineering Economist, 49, 185-197.

Hansen, P. (1972). The Accounting Concept of Profit, second ed. Amsterdam: North-Holland.

Harcourt, G.C. (1965). The accountant in a golden age. Oxford Economic Papers, 17(1), 66-80.

Hazen, G.B. (2003). A new perspective on multiple internal rates of return. The Engineering Economist, 48(1), 31-51.

Hazen, G.B. (2009, June). An extension of the internal rate of return to stochastic cash flows. Management Science, 55(6), 1030-1034

Herbst, A. (1978, June). The unique, real internal rate of return: Caveat emptor. Journal of Financial and Quantitative Analysis, 13, 363-370.

Hirshleifer, J. (1958, August). On the theory of optimal investment decision. Journal of Political Economy, 66, 329-352.

Hotelling, H. (1925, September). A general mathematical theory of depreciation. Journal of the American Statistical Association, 27-38. Reprinted in Brief R.P. (Ed.), 1984. Depreciation and Capital Maintenance. New York, Garland Publishing, pp. 15-29.

Jean, W.H. (1968, March). On multiple rates of return. The Journal of Finance, 23, 187-191.

Kaplan, S. (1965, January/February). A note on a method for precisely determining the uniqueness or non-uniqueness of the internal rate of return for a proposed investment. The Journal of Industrial Engineering, 16, 70-71.

Kaplan, S. (1967, October). Computer algorithms for finding exact rates of return. Journal of Business, 40, 389-392.

Karmel, P.H. (1959, December). The marginal efficiency of capital. Economic Record, 35, 429-434.

Kay, J.A. (1976, November). Accountants, too, could be happy in the golden age: The accountants rate of profit and the internal rate of return. Oxford Economic Papers, 28(3), 447-460.

Kay, J.A., \& Mayer C.P. (1986). On the applications of accounting rates of return. The Economic Journal, 96 (March), 199-207.

Keynes, J.M. (1936). The General Theory of Employment, Interest and Money. London: MacMillan.

Kierulff, H. (2008). MIRR: A better measure. Business Horizons, 51, 321-329.

Lima e Silva, J., Sobreiro, V.A., \& Kimura, H. (2018). Pre-purchasing financing pool: Revealing the IRR problem. The Engineering Economist, 63(2), 193-217.

Livingstone, J.L., \& Salamon, G.L. (1970). Relationship between the accounting and the internal rate of return measures: A synthesis and an analysis. Journal of Accounting Research, 8(2) (Autumn), 199-216.

Lorie, J., \& Savage, L.J. (1955, October). Three problems in capital budgeting. Journal of Business, 28, 229-239.

Lücke, W. (1955). Investitionsrechnungen auf der Grundlage von Ausgaben oder Kosten. Zeitschrift für betriebswirthschaftliche Forschung, 7, 310-324.

Luckett, P.F. (1984). ARR vs. IRR: A review and an analysis. Journal of Business Finance \& Accounting, 11(2) (Summer), 213-231.

Lundholm, R., \& O'Keefe, T. (2001). Reconciling value estimates from the discounted cash flow model and the residual income model. Contemporary Accounting Research, 18(2), 311-335. 
Magni, C.A. (2003). Decomposition of net final values: Systemic Value Added and residual income. Bulletin of Economic Research, 55(2), 149-176.

Magni, C.A. (2009a, October). Splitting up value: A critical review of residual income theories. European Journal of Operational Research, 198(1), 1-22.

Magni, C.A. (2009b, December). Investment decisions, net present value and bounded rationality. Quantitative Finance, 9(8), 967-979.

Magni, C.A. (2010a, May). Residual income and value creation: An investigation into the lost-capital paradigm. European Journal of Operational Research, 201(2), 505-519.

Magni, C.A. (2010b). Average Internal Rate of Return and investment decisions: A new perspective. The Engineering Economist, 55(2), 150-181.

Magni, C.A. (2011). Aggregate Return on Investment and investment decisions: a cash-flow perspective. The Engineering Economist, 56(2), 181-182.

Magni, C.A. (2012). In search of the "lost capital". A theory for valuation, investment decisions, performance measurement. Frontiers in Finance and Economics, 9(1), 87-146.

Magni, C.A. (2013). The Internal-Rate-of-Return approach and the AIRR paradigm: A refutation and a corroboration. The Engineering Economist, 58(2), 73-111.

Magni, C.A. (2014a). Mathematical Analysis of Average Rates of Return and Investment Decisions: The Missing Link. The Engineering Economist, 59(3), 175-206.

Magni, C.A. (2016, December). Capital depreciation and the underdetermination of rate of return: A unifying perspective. Journal of Mathematical Economics, 67, 54-79.

Martin, J.D., \& Petty, J.W. (2000). Value Based Management. The Corporate Response to Shareholder Revolution. Boston, MA: Harvard Business School.

Martin, J.D., Petty, J.W., \& Rich, S.P. (2003). An analysis of EVA and other measures of firm performance based on residual income. Hankamer School of Business working paper. Retrieved from http://papers.ssrn.com/sol3/papers.cfm?abstract id=41212

Mohnen, A. (2003). Managerial performance evaluation with residual income - limited investment budget and NPV maximization. Retrieved from http://ssrn.com/abstract $=481203$

Mohnen, A., \& Bareket, M. (2007, March). Performance measurement for investment decisions under capital constraints. Review of Accounting Studies, 12(1), 1-22.

Muliere, P., \& Parmigiani, G. (1993). Utility and means in the 1930s. Statistical Science, 8(4), 421-432.

Norstrøm, C.J. (1972, June). A sufficient condition for a unique non-negative internal rate of return. Journal of Financial and Quantitative Analysis, 7(3), 1835-1839.

O'Hanlon J., \& Peasnell, K.V. (2002). Residual income and value creation: the 'missing link'. Review of Accounting Studies, 7(2/3), 229-245.

Ohlson, J.A. (1989). Accounting earnings, book values, and dividends: The theory of the clean surplus equation in equity valuation. Unpublished manuscript. Reprinted in R. Brief \& K.V. Peasnell (Eds.), A Link Between Accounting and Finance. New York: Garland, 1996.

Ohlson, J.A. (1995). Earnings, book values, and dividends in equity valuation. Contemporary Accounting Research, 11(2) (Spring), 661-687.

Peasnell, K.V. (1981, June). On capital budgeting and income measurement. Abacus, 17(1), 52-67.

Peasnell, K.V. (1982a). Some formal connections between economic values and yields and accounting numbers. Journal of Business Finance \& Accounting, 9(3), 361-381.

Peasnell, K.V. (1982b, April). Estimating the internal rate of return from accounting profit rates. The Investment Analyst, 26-31.

Peasnell, K.V. (1996). Using accounting data to measure the economic performance of firms. Journal of Accounting and Public Policy, 15(4) (Winter), 291-303.

Peccati, L. (1987, September). DCF e risultati di periodo [DCF and period results], Proceedings of the XI AMASES Conference (Association for Mathematics Applied to Economic and Social Sciences), Aosta, Italy, 9-11. 
Peccati, L. (1989, March). Multiperiod analysis of a levered portfolio. Decisions in Economics and Finance, 12(1), 157-166. Reprinted in J. Spronk \& B. Matarazzo (Eds.), 1992, Modelling for Financial Decisions. Berlin: Springer-Verlag.

Penman, S. (1992). Return to fundamentals. Journal of Accounting Auditing and Finance (Reprinted in Brief, R., Peasnell, K.V., (Eds.), 1996. Clean Surplus: A Link Between Accounting and Finance. Garland Publishing, New York and London, pp. 233-251.

Penman, S. (2007). Financial Statement Analysis. Security Analysis and Security Valuation, third edition. McGraw-Hill Irwin.

Pfeiffer, T. (2000, January). Good and bad news for the implementation of shareholder-value concepts in decentralized organizations. Schmalenbach Business Review, 52(1), 68-91.

Pfeiffer, T. (2004, September). Net present value-consistent investment criteria based on accruals: A generalisation of the residual income-identity. Journal of Business Finance \& Accounting, 31(7/8), 905-926.

Pfeiffer, T., \& Schneider, G. (2007). Residual income-based compensation plans for controlling investment decisions under sequential private information. Management Science, 53(3), 495-507.

Pitchford, J.D., \& Hagger, A.J. (1958, December). A note on the marginal efficiency of capital. The Economic Journal, 68, 597-600.

Poincaré, J-H. (1902). La Science et L'Hypothése. Paris: Flammarion.

Preinreich, G. (1936). The fair value and yield of common stock. The Accounting Review. Reprinted in R. Brief \& K.V. Peasnell (Eds.) 1996. Clean Surplus: A Link Between Accounting and Finance. New York and London: Garland Publishing.

Preinreich, G. (1937, September). Valuation and amortization. The Accounting Review, 12(3), 209-226.

Preinreich, G. (1938). Annual survey of economic theory: the theory of depreciation. Econometrica, 6(1), 219-241.

Promislow S.D., \& Spring, D. (1996). Postulates for the internal rate of return of an investment project. Journal of Mathematical Economics, 26(3), 325-361.

Quine. W.V. (1951). Two dogmas of empiricism. The Philosophical Review, 60, 20-43.

Rajan, M.V., Reichelstein, S., \& Soliman, M.T. (2007). Conservatism, growth, and return on investment. Review of Accounting Studies, 12, 325-370.

Ramsey, J.B. (1972, September/October). The marginal efficiency of capital, the internal rate of return, and net present value: An analysis of investment criteria. Journal of Political Economy, 78(5), $1017-1027$.

Rappaport, A. (1986). Creating Shareholder Value: The New Standard for Business Performance. New York: The Free Press.

Reichelstein, S. (1997). Investment decisions and managerial performance evaluation. Review of Accounting Studies, 2(2), 157-180.

Rocabert, J.P., Tarrío, J.A., \& Pérez, M.J. (2000). Anomalies in net present value calculations. A solution Revista de Economía Pública, 173(2), 47-60.

Rogerson, W.P. (1997). Intertemporal cost allocation and managerial investment incentives: A theory explaining the use of Economic Value Added as a performance measure. Journal of Political Economy, 105(4), 770-795.

Ross, S.A., Spatt, C.S., \& Dybvig P.H. (1980, August). Present values and internal rates of return. Journal of Economic Theory, 23, 66-81.

Salamon, G.L. (1985, June). Accounting rates of return. American Economic Review, 75(3), 495-504.

Samuelson, P.A. (1946, May). Some aspects of the pure theory of capital. Quarterly Journal of Economics, 51, 469-496.

Schlick, M. (1931). Die Kausalität in der gegenwärtigen Physik, Die Naturwussenschaften, 13. Reprinted in M. Schlick, Gesetz, Kausalität und Wahrscheinlichkeit. Wien: Gerald \& Co, 1948.

Scott, A.D. (1953). Notes on user cost. The Economic Journal, 63, 368-384.

Simon, H. (1955). A behavioral model of rational choice. Quarterly Journal of Economics, 69, 99-118.

Simon, H. (1957). Models of Man. New York: Wiley. 
Solomon, E. (1956, April). The arithmetic of capital budgeting decisions. Journal of Business, 29, 124129.

Solomon, E. (1966). Return on investment: The relationship of book-yield to true yield. In R.K. Jaedicke, Y. Ijiri, O. Nielsen (Eds.), Research in Accounting Measurement. American Accounting Association.

Solomons, D. (1965). Divisional Performance: Measurement and Control. Richard D. Irwin, Homewood, IL.

Soper, C.S. (1959, March). The marginal efficiency of capital: A further note. The Economic Journal, 69, $174-177$.

Stark, A.W. (1989, March). A note on the aggregation properties of Hotelling depreciation. British Accounting Review, 21, 69-76.

Stark, A.W. (2004, December). Estimating economic performance from accounting data-A review and a synthesis. The British Accounting Review, 36(4), 321-343

Stewart, G.B. (1991). The Quest for Value: The EVA ${ }^{T M}$ Management Guide. HarperCollins Publishers Inc.

Teichroew, D., Robichek, A.A., \& Montalbano, M. (1965a, January). Mathematical analysis of rates under certainty. Management Science, 11(3), 395-403.

Teichroew, D., Robichek, A.A., \& Montalbano, M. (1965b, November). An analysis of criteria for investment and financing decisions under certainty. Management Science, 12(3), 151-179.

Vatter, W.J. (1966, October). Income models, book yield, and the rate of return. The Accounting Review, 41(4), 681-698.

Weingartner, H.M. (1966). The generalized rate of return. The Journal of Financial and Quantitative Analysis, 1(3) (September), 1-29.

Whittington, G. (1988). The usefulness of accounting data in measuring the economic performance of firms. Journal of Accounting and Public Policy, 7(4), (Winter), 261-266.

Wright, J.F. (1959, December). The marginal efficiency of capital. The Economic Journal, 69, 813-816.

Young, S.D., \& O’Byrne, S.F. (2001). EVA and Value-Based Management. McGraw-Hill.

\section{APPENDIX}

We proof that if a project belongs to the class of Soper projects, then the IRR margin is positive if and only if the ARR margin is positive.

(Necessity). The inequality $i-r>0$ is equivalent to

$$
\begin{aligned}
& b_{1}^{*}=b_{0}(1 \quad)-F_{1}<b_{0}(1 \quad i)-F_{1}=h_{1} \\
& b_{2}^{*}=b_{1}^{*}(1 \quad)-F_{2}<h_{1}(1 \quad)-F_{2}=h_{2} \\
& b_{T-1}^{*}=b_{T-2}^{*}(1 \quad)-F_{T-1}<h_{T-2}(1 \quad)-F_{T-1}<h_{T-1}
\end{aligned}
$$

which means $\sum_{t=1}^{T} b_{t-1}^{*}<\sum_{t=1}^{T} h_{t-1}=H$; since the project is a Soper project, then $H>0$, which implies $\bar{\varrho}(H)-\bar{a}(H)=\frac{r\left(\sum_{t=1}^{T} b_{t-1}^{*}\right)}{H}-\bar{a}(H)<r-\bar{a}(H)=r-i \quad 0$.

(Sufficiency). Suppose $\bar{a}(H)-\bar{\varrho}(H)>0$; then, it cannot be $i-r \leq 0$, otherwise one would find $\sum_{t=1}^{T} b_{t-1}^{*} \geq H \quad 0$, which would imply $\bar{\varrho}(H)=\frac{r\left(\sum_{t=1}^{T} b_{t-1}^{*}\right)}{H} \geq r>i=\bar{a}(H)$; but this contradicts the assumption. 